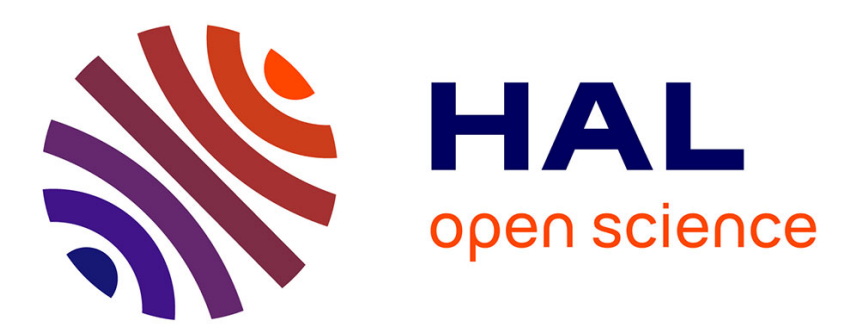

\title{
Evidence for fluvial and glacial activities within impact craters that excavated into a Noachian volcanic dome on Mars
}

Harish Harish, S. Vijayan, N. Mangold

\section{- To cite this version:}

Harish Harish, S. Vijayan, N. Mangold. Evidence for fluvial and glacial activities within impact craters that excavated into a Noachian volcanic dome on Mars. Icarus, 2021, 361, pp.114397. 10.1016/j.icarus.2021.114397 . hal-03376416

\section{HAL Id: hal-03376416 https://hal.science/hal-03376416}

Submitted on 13 Oct 2021

HAL is a multi-disciplinary open access archive for the deposit and dissemination of scientific research documents, whether they are published or not. The documents may come from teaching and research institutions in France or abroad, or from public or private research centers.
L'archive ouverte pluridisciplinaire HAL, est destinée au dépôt et à la diffusion de documents scientifiques de niveau recherche, publiés ou non, émanant des établissements d'enseignement et de recherche français ou étrangers, des laboratoires publics ou privés. 
1 Evidence for fluvial and glacial activities within impact craters that excavated into a

2 Noachian volcanic dome

3 Harish $^{1,2}$, S Vijayan ${ }^{1}$, and N Mangold ${ }^{3}$

$4 \quad{ }^{1}$ Planetary Science Division, Physical Research Laboratory, Ahmedabad 380009, India

$5 \quad{ }^{2}$ Indian Institute of Technology, Gandhinagar 382355, India

$6{ }^{3}$ Laboratoire de Planétologie et Géodynamique, Nantes, CNRS UMR6112, Université de Nantes,

7 Université d'Angers, 44322 Nantes, France

8

9

10 Corresponding author:

11 S Vijayan

12 email: vijayan@prl.res.in, vijayansiva@gmail.com

13

14

15

16

17

18

19

20

21

22

23 
26 Highlights:

27 1. Impact craters Degana and Degana-A excavated into a Noachian volcanic dome

28 2. New observations of multiple alluvial fans, moraine-like ridges within these craters

29 3. Olivine and LCP exposed by these impact craters reveal the composition of volcano

304 . Snow/ice is the likely source for post-Noachian fluvial and glacial activities

31

32

33

34

35

36

37

38

39

40

41

42

43

44

45

46 
Abstract:

Impact craters on Mars preserve diverse records of volcanic, fluvial, and glacial activities. Enigmatically, the preservation of these major activities or records altogether within impact craters is rare. We report one such new observation of impact craters that formed on a volcanic dome studied using data from the Mars Reconnaissance Orbiter's (MRO) Context Camera (CTX), HighResolution Imaging Science Experiment (HiRISE), and Compact Reconnaissance Imaging Spectrometer for Mars (CRISM), Mars Global Surveyor's Mars Orbiter Laser Altimeter (MOLA), and Mars Express' High-Resolution Stereo Camera (HRSC). A 20 km diameter impact crater, informally named as Degana-A, is formed within the $\sim 50 \mathrm{~km}$ diameter impact crater Degana. Mineralogical analysis reveals exposures of low-calcium pyroxene and olivine deposits, which occupy Degana-A's eastern walls, leading to the idea that pristine Noachian bedrocks might be exposed from beneath the volcanic dome. Degana-A floor is completely covered by alluvial fans from all sides with distributaries. Within Degana crater, multiple fans are observed along its eastern to southern side only. The most likely source of water was the accumulation of snow on Degana crater walls, which possibly melted as a result of the impact of Degana-A. We observed a

$62 \sim 1 \mathrm{~km}$ wide breach on the eastern wall of Degana-A and the estimated maximum flow velocity is $63 \sim 2 \mathrm{~m} / \mathrm{s}$ and a run-off $\sim 2.25 \mathrm{~mm} / \mathrm{hr}$. Over the south-facing walls, multiple moraine-like ridges 64 superposed the fans, which suggests overprinting by glacial activities. The presence of fans and 65 superposed moraine-like ridges located at the mid-latitudes $\left(\sim 23^{\circ} \mathrm{S}\right)$ implies atmosphere-derived 66 snow/ice precipitation was possible. Chronologically, the dome is of Noachian age, whereas 67 Degana crater formed in the Hesperian period and crater retention on the fans indicates late Hesperian to Amazonian ages. Overall, the preserved Noachian crustal material underneath a volcanic dome is rarely exposed in its pristine context, which offers a rare window into early igneous processes. This intriguing location also witnessed a climatic transition as implied by 


\section{Introduction}

77 Sedimentary deposits on Mars retain the record of ancient environments and prevailing climatic conditions (Moore and Howard, 2005; Kraal et al., 2008; Blair and McPherson, 2009; Grant and Wilson, 2011; Morgan et al., 2012; Morgan et al., 2014; Wilson et al., 2021). Sedimentary deposits are more developed in the Late Noachian and Early Hesperian epochs, where they are frequently associated with widespread mineralogical assemblages as observed in-situ at Gale crater (e.g., Bristow et al., 2018) and from orbit (e.g., Carter et al., 2013). However, among the various sedimentary deposits observed on Mars, mid-latitude alluvial fans date predominantly from the Late Hesperian-Early Amazonian epochs, so they are of great interest as they represent fluvial activity that occurred after a potential climatic optimum of the Noachian (Moore and Howard, 2005; Kraal et al., 2008; Grant and Wilson, 2011; Morgan et al., 2012; Mangold et al., 2012a,b; Kite et al., 2017; Wilson et al., 2021). Although many studies have described alluvial fans, their origin remains debated among several hypotheses: snowmelt versus rainfall (e.g. Milton, 1973; Hoke and Hynek, 2009; Di Achille and Hynek, 2010a,b; Wordsworth et al., 2013; Kite et al., 2013), transient or stable climatic conditions (Moore and Howard, 2005; Armitage et al., 2011; Grant and Wilson, 2011,2012; Kite et al., 2017), the role of impact or volcanic activity in melting water ice (e.g., Gulick, 2001; Hauber et al., 2005; Williams et al., 2008; Ansan and Mangold, 2013). Thus, finding key locations to better understand these processes is an important challenge to provide answers on Martian climate change.

In this context, we present new observations of fluvial and glacial landforms in Degana crater $\left(23.72^{\circ} \mathrm{S}, 314.50^{\circ} \mathrm{E}\right.$ ), an impact crater that formed on a volcanic dome (Xiao et al., 2012) (Figure 1). Xiao et al. (2012) mapped almost all the ancient volcanoes on Mars, excluding the Tharsis region. Their study identified the region over which Degana crater is located as a huge Noachianage volcanic dome. They suggested these domes are mostly conical in shape and lack calderas. However, no direct observation has yet been made to show that they host fluvial deposits and glacial landforms. Likewise, no mineralogical analysis has been carried out over this volcanic dome to decipher the Noachian mineralogy. Thus, this region offers a unique chance to observe volcanic, impact, glacial, and fluvial landforms in the same location, assessing whether the processes that formed them occurred in concert or not. In addition, the composition of such Noachian volcanoes is critical to understand the evolution of ancient volcanic crust on Mars (Xiao 
et al., 2012). In this study, we will provide new information about the geological context and bedrock composition and characterize the morphology of the fluvial and glacial landforms. We established the relative stratigraphic relationships between the volcanic dome, impact craters, fluvial deposits, and glacial landforms within both impact craters. Then, we performed quantitative analysis on the fluvial and glacial landforms to constrain their extent and timing. Also, using cratersize frequency analysis, we determined the apparent ages of these processes. At last, we discuss the formation hypothesis for the fluvial and glacial deposits and the climatic evolution of Mars.

\section{Data and Methods}

For the geomorphological analysis, we used $\sim 6 \mathrm{~m} / \mathrm{px}$ Mars Reconnaissance Orbiter (MRO)Context Camera (CTX), and $\sim 25 \mathrm{~cm} / \mathrm{px}$ MRO-High-Resolution Imaging Science Experiment (HiRISE) images (Malin et al., 2007; McEwen et al., 2007). For the topographic analyses, we used 463 m/px Mars Global Surveyor (MGS)-Mars Orbiter Laser Altimeter (MOLA) DEM (Smith et al., 2001), and the $200 \mathrm{~m} / \mathrm{px}$ Mars Express (MEX)-High-Resolution Stereo Camera (HRSC) - MGS MOLA blended DEM (Fergason et al., 2018). We also used high-resolution CTX DEM and HiRISE DEMs (wherever available), generated using the open-source pipeline of MarsSI (Quantin-Nataf et al., 2018).

For the mineralogical analysis, we used data by the MRO-Compact Reconnaissance Imaging Spectrometer for Mars (CRISM), a hyperspectral camera (Murchie et al., 2007). CRISM used two detectors with 544 channels in the visible to the near-infrared spectral region $(0.4$ to $4.0 \mu \mathrm{m})$ (Murchie et al., 2007). In this study, CRISM data analysis was performed using both S-detector (VNIR) and L-detector (IR) datasets (Murchie et al., 2007). The short wavelength (VNIR) data ranges from 0.36 to $1.05 \mu \mathrm{m}$, while the long-wavelength (IR) data ranges from 1.0 to $3.92 \mu \mathrm{m}$. The analysis was performed using the CRISM Analysis Toolkit (CAT) plug-in added to ENVI 4.5. CRISM observations were converted into I/F reflectances by applying corrections for instrumental artifacts (Murchie et al., 2007). Degana crater includes only one full resolution targeted (FRT00023F32), which was processed to correct for photometric, and atmospheric noise in the spectral data using the method suggested by Murchie et al. (2007) and Flahaut et al. (2010).

For identifying the composition, we used the spectral parameters OLINDEX2, LCPINDEX, and HCPINDEX mentioned in Viviano-Beck et al. (2014). OLINDEX2 is the modified olivine parameter that measures olivine's $1.0 \mu \mathrm{m}$ band depth in the presence of spectral slopes (Salvatore 
et al., 2010). LCPINDEX and HCPINDEX are the low Calcium-pyroxene and high Calciumpyroxene parameters, respectively, that measure the pyroxene's $1.0 \mu \mathrm{m}$ and $2.0 \mu \mathrm{m}$ band depth (Pelkey et al., 2007). The regions highlighted in spectral parameters were examined in more detail to get a diagnostic spectral signature. Areas with strong spectral absorption signatures were used to determine the region of interest (ROI) and spectra were taken from ROIs of several pixels. We used a minimum of $3 * 3$ pixels ROI for each average spectrum considered in this study (Table 1). We used spectral data in the wavelength range from 0.5 to $2.6 \mu \mathrm{m}$ by integrating the VNIR and IR data to confirm the mineral absorptions of the Fe-bearing phases, which generally turned up around $1 \mu \mathrm{m}$ (Sun and Milliken, 2015). The selected ROI spectra were ratioed with the neutral spectra, mostly a dust-rich area obtained from the same column (Ehlmann et al., 2009) to enhance the spectral features. We calculated the ratioed spectra for each detector (VNIR and IR) separately and then integrated them. We also removed the overlapping spectral data from 1.0 to $1.05 \mu \mathrm{m}$ in the S-detector and L-detector datasets as suggested by Murchie et al. (2007).

\section{Observations and Interpretations}

\subsection{Geologic context and bedrock composition}

\subsubsection{Geologic context and volcanic dome}

The study area (Figure 1a) is located at the easternmost side of the Coprates quadrangle in the southern highlands of Mars (McCauley, 1978). Figure 1a shows the geologic context of the area of study, which shows an elevated area similar to a dome. This dome extends more than $200 \mathrm{~km}$ in diameter (Figure 2a). Many impact craters of varying diameters superimpose the dome (Figure 1). The largest crater on the western flank of the volcanic dome is the Degana crater whose diameter and depth are $\sim 50 \mathrm{~km}$ and $\sim 2 \mathrm{~km}$, respectively. Another impact within the Degana crater leads to form a $\sim 20 \mathrm{~km}$ diameter crater, and depth of $\sim 0.7 \mathrm{~km}$, which is named in this study as 'Degana-A' (Figure 2b).

Degana crater and its surrounding region are mapped as Mid-Noachian highland units (Figure 1b), which hosts undifferentiated materials formed by volcanic and impact activity (Scott and Tanaka, 1986; Tanaka et al., 2014). Also, this unit is identified as moderately to heavily degraded, heavily cratered, hosts dense valleys, grabens, and wrinkle ridges (Scott and Tanaka, 1986; Tanaka et al., 2014). Xiao et al. (2012) categorized this dome structure as a shield volcano. The dome is 
165

166

167

168

169

170

171

172

173

174

175

176

177

178

179

180

181

182

183

184

185

186

187

188

189

190

191

192

193

embayed on its edge by Late Noachian volcanic plains, which contain wrinkle ridges as typically observed in Late Noachian and Hesperian plains of Coprates Planum (Tanaka et al., 2014). Tanaka et al. (2014) have mapped two valley networks in the region. The valley network in the south-west is Her Desher Vallis, whereas the other valley network has been mapped on the eastern flank of the dome (Figure 1b).

An elevation profile AA' (north to south) taken along this volcanic dome shows typical domical topography (Figure 2a). The elevated dome stands $\sim 1.2 \mathrm{~km}$ above the adjoining plain surface (Figure 2a), whereas, the craters Degana (Figure 3a) and Degana-A (Figure 3b) have excavated $\sim 1.5 \mathrm{~km}$ below the regional baseline defined by the reference elevation of the plain surface adjacent to the dome. Overall, the two craters in combination penetrated $\sim 2.7 \mathrm{~km}$ deep into the dome (Figure 2b). Considering the surrounding plains, the surface elevation at the time of dome formation might be $\sim 500 \mathrm{~m}$. It means Degana-A reached a terrain deeper than the surface that exists before dome formation, i.e. an outcrop could be exhumed from the primitive crust below the volcanic dome or from a crystallized magma chamber beneath the dome. If the surrounding plains are thicker than $1.5 \mathrm{~km}$, the outcrop would be exhumed from the deep part of the volcanic dome. In both cases, this observation provides an opportunity to analyze the pristine bedrock of Mars, which is preserved from the middle-Noachian epoch (Xiao et al., 2012). Apart from Degana and Degana-A craters, the other circular features atop the dome (Figure 1) are unnamed craters marked in Robbins and Hynek (2012)'s impact crater database. These four large craters are superposed over the volcanic dome, as shown in (Figure 3). The diameter of these craters ranges from $\sim 20$ $\mathrm{km}$ to $40 \mathrm{~km}$. In this study, the four craters are named unnamed craters A, B, C, and D (hereafter referred to as UA, UB, UC, and UD) (Figure 1a). Figure 3c-f shows the four individual craters with their raised rims and relatively distinguishable ejecta from two of them (Figure 3e,f). Based on their raised rims and ejecta, we interpret these craters as impact craters (Figures 1a,3) and not as volcanic features.

\subsubsection{Bedrock mineralogy}

The exposed bedrock material from the two superposed craters is analyzed using CRISM data. Before analyzing the individual CRISM spectra, we derived the CRISM color composite map or spectral parameter map according to Viviano-Beck et al. (2014) by using the OLINDEX2, 
LCPINDEX, and HCPINDEX. This derived color composite image is overlaid over the CTXDEM (Figure 4a) to assess the compositional variation observed within the crater. This RGB combination of spectral parameters (OLINDEX2, LCPINDEX, and HCPINDEX) shown in Figure 4a highlights potential olivine-rich regions in red color, low-calcium pyroxene (LCP) regions as green/cyan and high-calcium pyroxene (HCP) regions as blue color as suggested by Viviano-Beck et al. (2014).

From these highlighted regions, we have chosen spectra from 9 ROIs (Figure 4a), which are mostly located on the northeastern and southeastern wall/rim of Degana-A. The locations of all the numerator spectra, denominator spectra, and the ROI sizes are given in Table 1. These are the locations where the diagnostic absorption features in the spectra are distinguishable. Spectra signature from the northeastern rim of Degana-A shows (Figure 4b) a broad absorption near $1 \mu \mathrm{m}$ and $2 \mu \mathrm{m}$ wavelength. Absorptions around 1 and $2 \mu \mathrm{m}$ are spectrally identified as pyroxene, where the band centers strongly dependent on the Ca content (Adams, 1974; Cloutis et al., 1986; Cloutis and Gaffey, 1991; Klima et al., 2007). All the colored spectra from the green/cyan region (Figure 4a,b) exhibit a strong absorption feature between $0.8-1.0 \mu \mathrm{m}$, indicating that the ferrous phase is plausibly low-calcium pyroxene (LCP) (Huang et al., 2012). An additional broad absorption before $2 \mu \mathrm{m}$ (Figure $\mathbf{4 b}$ ) implies the presence of low-calcium pyroxene as distinguished elsewhere on Mars (Mustard et al., 2005; Skok et al., 2012; Clenet et al., 2011b). We have observed that LCP is widespread over this part of the north-eastern rim (Figure 4a,b). Among the six identified locations of LCP detections, spectra P1, P2, and P6 are located on the northeastern rim. LCP identified in locations P3 and P4 is exposed along the eroded walls of the valleys, which are connected to the east rim of Degana-A. The LCP spectra obtained from P5 are located on the south-eastern wall of Degana-A crater (Figure 4a). The LCP ratioed CRISM I/F reflectance spectra obtained from the six ROIs matches with RELAB (Viviano-Beck et al., 2015) representative spectra of low-calcium pyroxene (Figure $\mathbf{4 b}$ ).

The other diagnostic spectra are obtained from the south-eastern wall of Degana-A crater. Figure $4 \mathbf{c}$ shows a broad absorption around $1 \mu \mathrm{m}$ and no other diagnostic absorption at other wavelengths. A broad absorption around $1 \mu \mathrm{m}$ in the near-infrared region and a lack of absorption around $2 \mu \mathrm{m}$ is indicative of olivine where the band center is dependent on the relative content of $\mathrm{Fe}$ and $\mathrm{Mg}$ (Burns, 1970; King and Ridley, 1987; Sunshine and Pieters, 1998). The spectra shown in 
224 Figure $4 \mathbf{c}$ indicate absorption around shorter wavelengths $(<1 \mu \mathrm{m})$, which is due to an increase in

225 Mg content (Ody et al., 2013). In addition, the absence of strong absorption between 1.2-1.4 $\mu \mathrm{m}$

226 (Figure 4b) also indicates that the olivine is richer in $\mathrm{Mg}$ (e.g., Huang et al., 2012). This suggests

227 that this potential olivine outcrop is consistent with Mg-rich olivine (Figure 4c). Spectra O1 and

$228 \mathrm{O} 2$ in Figure 4c exhibit olivine signatures within Degana crater, whereas, the spectra shown in 229 black is the lab spectrum of Mg-rich olivine (Forsterite) from RELAB (Viviano-Beck et al., 2015).

230 We have observed similar absorptions at location O3 (Figure 4a). Although the olivine mineral 231 exposures are spatially prevalent on the south-eastern wall of Degana-A, isolated patches have also 232 been observed on the north-eastern wall in the color composite image (Figure 4a). We have also 233 used the CRISM CAT tool associated Modified Gaussian Model (MGM) to estimate the cation 234 compositions of the pyroxene mineral (Sunshine et al., 1990). Using MGM we determined the 235 236 normalized $\mathrm{LCP} /(\mathrm{LCP}+\mathrm{HCP})$ ratio, which remains high (>70\%) in most of the locations, as shown in Figure S1. This analysis suggests that the proportion of LCP is high within Degana crater in comparison to other mafic minerals. Overall, the minerals identified using CRISM are dominated by primary mafic minerals (e.g. Viviano-Beck et al., 2015). However, we have not detected any hydrated minerals within the fan deposits or along the eroded walls of valleys. The complete lack of hydrated minerals is possibly caused by dust mantling on the floor, or by the limited area covered by the single CRISM cube, so the presence of hydrated minerals cannot be ruled out.

Figure 5 shows the HiRISE RGB and greyscale images locations where CRISM mineral spectra were obtained. Figure 5a,b shows the locations of LCP exposures in false-color images by HiRISE, as indicated by cyan coloring (Sun and Milliken, 2015). We have also observed distinct spectral absorptions over the light-toned outcrop (Figure 5c), which is identified as a possible olivine exposure (Figure 4c) on the inner crater wall. In addition, olivine exposures were identified along the inner crater wall of Degana-A (Figure 5d) in the greyscale HiRISE images. Interestingly, all the LCP and olivine detected within the craters are linked to either the inner crater wall or the proximal part of the valley. Overall, the notable mafic signatures are observed along the rim of Degana-A crater, where the slope is high enough $\left(>30^{\circ}\right)$ to expose these signatures. This suggests that the elevated region of the inner crater wall and the adjoining valley wall exposed the mafic minerals due to their steep slope and possible erosion. It also suggests that a significant portion of the mafic minerals is blanketed by alluvial deposits in other areas. The presence of LCP on the northeastern and southeastern wall of Degana-A crater indicates a continuous layer along the rim 
that was exposed by the impact. This small exposure, although dust-covered, allows us to infer the mineral composition exposed within this dome. Thus, we infer these exposed mineral units to be pristine Noachian crust uplifted by volcanic dome formation.

\subsection{Morphology of fan deposits}

We mapped the occurrence and extent of fan deposits, valleys, and ridges within the crater (Figure 6). The four fan deposits within Degana-A crater cover the entire floor area (Figure 6a,b). The fan deposits are also observed on the floor of Degana crater, especially in the southwestern quadrant of the crater (Figure 6b). Figure 6b shows the geomorphic map of the impact craters and their diverse features. Figure 7 shows six prominent fan deposits formed within Degana-A and Degana craters, and their corresponding area, fan length, and slope gradient are given in Table 2.

We observed several channels with positive relief on the fans (Figure 7). These channels are consistent with original distributary, where the positive relief likely formed as a result of the finer surrounding material being removed by the wind. The fans within Degana crater (Figure 7) host several distributaries. Some of these distributaries present on the fans' surface are marked by white arrows (Figure 7). We observed that these distributaries are mostly radiating away from the fan apex (Figure 7). The toe regions of the fans located within Degana-A fused with each other (Figures 6,7). Within fans (f1-f4), multiple distributaries are observed and they vary in their extent and width. These distributaries are few kilometers long and a couple of meters wide (Figure 7). The fans within the Degana-A are of low gradients in the range of $2^{\circ}$ to $4^{\circ}$ (Table 2), and the four fans have almost equal areas (Table 2). In almost every fan deposit (Figure 7a-d), near the apex region, the distributaries appear in a cluster, whereas away from the apex region towards the downstream, they are apart from each other and observed to follow the typical topographic driven flow. The distributaries are oriented downslope, and they are aligned along with the fan orientation (Figure 7d). The fans located on the floor of Degana crater (Figure 7e,f) did not show as many sharp distributaries as observed on the fans located within Degana-A. The distributaries are observed only at the termini of fans f5 and f6 (Figure 7 e, f), and they are mantled by a dust cover. Interestingly, Figure 7e shows the possible coalescing of two fans in the toe region. Dust cover and transverse aeolian ridges (TAR) (Wilson and Zimbelman, 2004; Berman et al., 2011) were observed to fill the intermediate troughs within the fan deposits. 
Figure 8a shows the HiRISE DEM of surface features of fan $\mathrm{f} 1$, where the prominent distributaries are radiating from the fan apex. The elevation gradient along the distributaries can be seen in the HiRISE DEM. Though all the distributaries are sourced from the apex points, some of them are discontinuous. Figure $\mathbf{8 b}$ shows a topographic profile with varying elevations along a distributary within fan f1, which has a relief of $\sim 10 \mathrm{~m}$. Figure 8c shows distributaries on fan f1, which are often stacked, exhibiting crosscutting and superposition relationships. We have also observed that the width of these distributaries decreases as we move farther from the apex (Figure 8c). These distributaries over the Degana fans are up to 10s of meters thick. The observed crosscutting of the distributaries is the most prominent intersection at an acute angle that occurred within fan $\mathrm{fl}$ (Figure 8c). The distal portion of this distributary is discontinuous (Figure 8b) and terminates abruptly.

Apart from distributaries, the fans in Degana-A, particularly fans f1 and f3 (Figure 8c,d) exhibit surface textures with noticeable bedding/layered sediments. Fan f1 hosts many distinguishable stratigraphies (Figure 8c,d) observed at the distributary termini and along the intermediate region between the distributaries. Figure 8d also shows that the layering is evident along the flanks of the distributaries located on the fan f1. These layers are 100s of meters long, and the entire sequence is 10s of meters thick. Also, the source area of fan $\mathrm{f} 3$ on the western crater wall (Figure 9) shows well-exposed layers along the flanks of the distributary. The distributary flank hosts notable small boulders resolvable in HiRISE color images (Figure 9).

On observing fan $\mathrm{f} 1$ apex region, a significant part of the crater rim was breached and this breach is associated with five valleys, which originated from Degana's crater wall (Figure 10a). Over this part of the Degana-A crater rim, we observed that the rim height is $\sim 800 \mathrm{~m}$ towards the northern side, whereas it is $\sim 920 \mathrm{~m}$ towards the southern side. We observed $\sim 800 \mathrm{~m}$ of the wall has been eroded and made as an inlet for the fan $\mathrm{f} 1$ deposits. Nearly all five valleys converge outside the eastern wall of Degana-A crater (Figure 10a) and breach this part to form the f1 fan deposits. Figure 10b shows one of the valleys from the Degana eastern wall with exposed layering in the HiRISE color image. This we observe as the earlier deposited sediments over the eastern floor of Degana were incised, possibly during the Degana-A rim breaching.

On observing the distal fan $\mathrm{f} 2$, we found that it has coalesced with the toe part of fan $\mathrm{f} 1$ (Figure 11a). Layers are observed at the toe region of both the fans $\mathrm{f} 1$ and $\mathrm{f} 2$, whereas at their coalescing 
part, hummocky materials are observed (Figure 11a). The region of coalescing can be identified by a rough-textured surface with an absence of distributaries (Figure 11a). Figure 11b shows distributaries (marked by black arrow) and layering (marked by white arrow) on fan f2. Fan f3 also shows evidence of distributaries (Figure 11b) and layering that are distinguishable (Figure 9). All the four fans within Degana-A have coalesced at their toe region or by their sides.

We also observed fan deposits over the walls of Degana crater (f5 to f9), which mostly terminate at the rim of the Degana-A crater (Figure 6b). The slopes of these fans are in the range of $2^{\circ}$ to $3^{\circ}$. Apparently, they have formed in the south and southeast of Degana-A and connected with the valleys presented on the wall of Degana (Figure 6b). Out of fans f5-f9, the smallest fan (f8) is $\sim 4$ $\mathrm{km}$ long and covers an area of $\sim 10 \mathrm{~km}^{2}$, while the largest fan (f6) is $\sim 12 \mathrm{~km}$ long and covers an area of $\sim 85 \mathrm{~km}^{2}$. Fan f5 is the second-largest fan within Degana crater though it is formed by deposits from multiple valleys (Table 2).

Based on Blair and McPherson's (1994, 2009) definition, alluvial fans are semi-conical depositional landforms that develop through a channel, and branching spreads the sediments across the surface. In general, alluvial fans are hundreds of meters to few kilometers long along their major axis and fed by constrained catchments. This definition applies well to the observed fan deposits (Figure 7) inside Degana and Degana-A craters.

\subsection{Ridges}

In Degana-A crater, we observed arcuate or wide U-shaped ridges located over fans f2 and f3 (Figure 13). Photo-geological observations and profiles across these ridges indicate positive relief features with knobs (Figures 13,14). They were observed to drape over the eroded wall and fan of the Degana-A crater (Figure 13). These ridges are 10s of kilometers long and 100s of meters wide. Two ridges in the center over fan $\mathrm{f} 2$ have merged and formed a thick ridge towards the west (Figure 13). Further to the west, we observed a discontinuity along this merged ridge (Figure 13). The ridges in Degana-A appear more degraded towards the eastern side (Figure 13). This ridge is relatively thicker in its center and the thickness decreases towards both of its frontal lobes (Figure 13). We have also observed that fan $\mathrm{f} 2$ is oriented from northwest to southeast, whereas these ridges are oriented in a northeast-southwest direction (Figure 13). Similar, but only $5 \mathrm{~km}$ long, ridges are also observed on the alluvial fan $\mathrm{f} 3$ (Figure 13). Interestingly, the ridges superposed the fan deposits and are observed on the pole-facing wall of Degana crater. The ridges in Degana and 
their characteristics such as convex geometry, an arcuate shape, and knobs are consistent with other moraines observed on Mars (Arfstrom and Hartmann, 2005; Shean, 2010; Scanlon et al., 2015).

We analyzed elevation profiles along north-south directions using the CTX DEM across the ridges located on fan $\mathrm{f} 2$ (no HiRISE DEM is available for this location). Four profiles were examined for which we determined the average thicknesses. The limited resolution of the CTX DEM does not allow extracting precise thicknesses for some of the ridges (Figure 14). These measured thicknesses vary from $8 \mathrm{~m}$ (BB') to $51 \mathrm{~m}$ (CC') (Figure 14, Table 4), and we have taken these values as a range for the possible ridge thickness. Further, we followed the approach by Hartmann et al. (2014), to estimate the ratio of basal stress $(\zeta)$ to density $(\rho)$, which provides information about the nature of a glacier. To calculate this ratio, we used Paterson's (1994) relation, which suggests a relationship between basal stress and the density given as:

$$
\zeta=\rho \mathrm{gh} \tan \alpha
$$

where $\mathrm{g}$ is the gravity $\left(3.72 \mathrm{~m} / \mathrm{s}^{2}\right)$, $\mathrm{h}$ is the height/thickness, and $\alpha$ is the slope in degrees (Paterson, 1994; Hartmann et al., 2014). The average and maximum thickness (h) measured for morainelike ridges over fan $\mathrm{f} 2$ are estimated as $\sim 22 \mathrm{~m}$ and $51 \mathrm{~m}$, respectively. The average and the maximum values are used because this region could have undergone erosion after their formation. Slope $(\alpha)$ values were also determined, along with all the profiles that are considered for thickness measurements (Table 3). We obtained the average ratio of basal stress to density for Degana glacier(s) as $\sim 4 \mathrm{~m}^{2} / \mathrm{s}^{2}$ (Table 3).

\subsection{Small polygonal patterns}

Within the Degana crater and on the fan deposits, several polygonal-shaped features are observed (Figure 15). Polygonal patterns are observed, especially on the fans in Degana-A, and also on the inner and outer eastern wall of Degana-A crater (Figure 15). The majority of polygons' boundaries or fractures observed on the fans appear irregular (Figure 15 a-c), whereas polygons over the Degana-A walls visually appear regular or organized to each other (Figure $15 \mathbf{d - f}$ ). These polygons are 10s of meters wide and the fracture length varies accordingly. Figure 15b shows polygons over the fan f1, with fractures cutting through several layers. The polygonal fractures are well distinguishable over the fan f1 and within the vertically exposed stratigraphy (Figure 15b). We 
have observed that over the fans (Figure 15 a,b) and the wall (Figure 15 d-e), most of the polygons are negative relief features. In contrast, Figure 15c shows a distinct style of polygons with filled ridges and positive reliefs in some areas on fan f1. Polygons in the wall of Degana-A (Figure 15d) are distinct from the polygons observed on the fans (Figure 15a-c) in terms of the slope at which they formed. Polygons shown in Figure 15a-c have formed on the relatively level floor $\left(<10^{\circ}\right)$, whereas polygons shown in Figure 15d have formed on the more inclined wall $\left(>30^{\circ}\right)$.

Overall, polygons on the fans suggest a potential involvement of volatiles potentially ice or adsorbed water in clay minerals, in their formation and, which would imply a periglacial environment postdating the deposition of the pile of sediments.

\subsection{Crater size-frequency distributions}

Xiao et al. (2012) estimated the age of the volcanic dome as $\sim 4 \mathrm{Ga}$. In this study, we used a Poisson timing analysis (Michael et al., 2016) to estimate the absolute model ages. We mapped the best visible ejecta boundary of Degana crater and counted the superposed craters over the ejecta (Figure 16a). Our crater count statistics over the ejecta (area $\sim 6546 \mathrm{~km}^{2}$ ) resulted in a total of 362 craters from $\sim 100 \mathrm{~m}$ to $20 \mathrm{~km}$. We obtained the best fit model age by fitting 17 craters, whose diameter is greater than $1.3 \mathrm{~km}$ (Figure 16b). From this, the age of Degana crater is $\sim 3.7 \mathrm{Ga}$ (early Hesperian) (Michael, 2013). Further, we analyzed the ejecta of Degana-A; however, it is very difficult to distinguish the ejecta, which is degraded by mass movement processes within the host crater Degana. The floor of Degana-A is almost entirely covered by sediment deposits (Figure 6) from all around the wall, occupying an area of $\sim 313 \mathrm{~km}^{2}$. Hence, we counted all the possible superposed and embedded craters (Figure S2) over these alluvial fans (f1-f4) and determined cumulative (Figure 16c) and differential (Figure 16d) crater size-frequency distributions. The cumulative and differential fan-derived crater size-frequency distribution for Degana-A is early Amazonian (Michael, 2013). This age is not the formation age of the fan deposits within DeganaA; rather, it is estimated from the craters retained after their formation. Also, the diverse erosion of fan ridges observed (Figure 11) shows the difficulty in determining the model fan age. We want to clarify here that this age is the crater retention age for all the alluvial fans and can only suggest a possible lower bound to the deposits within Degana-A. In addition, we estimated cumulative (Figure 16c) and differential (Figure 16d) fan-derived crater size-frequency distributions for the four fans (f5 to f9) located over the walls of Degana crater. The obtained age is also early 
Amazonian. This suggests that the fan deposits observed within both craters (Degana and DeganaA) are likely Amazonian.

\section{Discussion}

\subsection{Evidence for exposure of pristine Noachian crust}

The presence of mafic minerals in well-exposed outcrops within Degana crater indicates igneous lithology or basaltic/volcanic subsurface layers (e.g., Skok et al., 2012) exposed by the Degana and Degana-A impact. The following mechanisms have been proposed for the origin of olivine and LCP bearing rocks on Mars: Noachian crust/volcanism (Mustard et al., 2005; Hamilton and Christensen, 2005; Tornabene et al., 2008; Poulet et al., 2009a,b; Flahaut et al., 2012; Quantin et al., 2012; Skok et al., 2012; Rogers et al., 2018; Viviano-Beck et al., 2019) or impact melting from large impact basins (Mustard et al., 2007; Palumbo and Head, 2017). Noachian/early crust on Mars can contain evidence for its formation and crustal modification afterward (Skok et al., 2012). Mg-rich olivine got exposed on the wall/rim of Degana-A crater. McSween et al. (2006) suggested that Mg-enriched olivine on Mars likely indicates ancient primitive magmatic rock. Thus, the exposure of more mafic rocks in this region has implications for the magmatic history of the region. The exposed olivine and LCP in the uplifted rim of DeganaA provide a piece of direct evidence for the materials present in the interior of the volcanic dome. This strongly reveals that the materials exposed by the Degana outcrops represent either pristine Noachis crust and/or volcanic deposits sourced by a primitive mantle (McSween et al., 2006; Mustard et al., 2009; Skok et al., 2010; Flahaut et al., 2012; Quantin et al., 2012; Baratoux et al., 2013).

\subsection{The fate of water at Degana crater}

Earlier studies suggest regional glacial deposits in the southern highlands poleward of $30^{\circ} \mathrm{S}$ (Kargel and Strom, 1992; Head and Pratt, 2001; Ghatan and Head, 2002; Fastook et al., 2012; Scanlon et al., 2014; Head and Marchant, 2014; Fastook and Head, 2015; Kress and Head, 2015; Scanlon et al., 2015). While the glacial deposits around the Tharis volcanoes have got attention for the Amazonian equatorial ice (Sean et al., 2005; Forget et al., 2006), several craters located in low to mid-latitude $\left(\sim 5^{\circ}\right.$ to $\left.60^{\circ}\right)$ regions on Mars host young landforms on their floors and walls, which potentially indicate the involvement of ice-rich material with lobate 
tongues and arcuate ridges (Arfstrom and Hartmann, 2005; Head et al., 2005; Shean, 2010; Scanlon et al., 2015; Sinha and Vijayan, 2017; Hartmann et al. 2002, 2003).

Thus like other craters, the local deposition of atmospheric ice occurred within the Degana. The moraines observed within Degana-A crater, which is situated at $23^{\circ} \mathrm{S}$ latitude, provide crucial evidence of equatorward glacial deposits during the Amazonian period. Global climate models for the equatorial highlands region of Mars show the possibility of snow accumulation and melting over the low and mid-latitudes, which would enable fan formation by snowmelt hypothesis (Wordsworth et al., 2013; Kite et al., 2013). However, there is no unambiguous observation of glacial deposits connected to the alluvial fans. While the interpreted glacial landforms postdate the alluvial fans at Degana, the fact that glacial ice was able to be deposited during the Amazonian shows that this location was once favorable to snow precipitation in the past. The average ratio of basal stress to density for Degana glacier(s) (i.e. $\sim 4 \mathrm{~m}^{2} / \mathrm{s} 2$ ) in comparison to terrestrial values of pure ice glaciers $\left(40-100 \mathrm{~m}^{2} / \mathrm{s}^{2}\right)$ is one order of magnitude lower, but not so much lower than values of 3.7 to $44.5 \mathrm{~m}^{2} / \mathrm{s}^{2}$ found by Hartmann et al. (2014) at Greg crater. These low values are likely explained by the fact that these moraines underestimate the actual thickness of the past glaciers, but are consistent with pure-ice glaciers, while rock glaciers would show higher values and a partial filling by the residual material (Hartmann et al., 2014).

Morgan et al. (2014) documented distributaries within Saheki crater' fans as observed on Degana' fans (Figure 7), which are downslope oriented and show radiating outward patterns from the fan apex. Many other studies (Moore and Howard, 2005; Irwin et al., 2018; Boatwright and Head, 2019) reported similar ridges over the fans within many martian craters, which were interpreted as inverted channels or fan distributary ridges. Morgan et al. (2014) documented layered sediments within the Saheki crater and interpreted that overbank flows, which might have been sourced from multiple flows within the distributaries, have deposited these layered sediments. Distributaries have spread across the fans in Degana-A crater (Figure 7), and they were the potential source for layered sediments, as suggested by Morgan et al. (2014). The flanks of the discontinuous distributaries (Figures 8d,9) with layers are records of possible long-duration flow events in the region. Additionally, Morgan et al. (2014) suggested that such layers were exposed by aeolian erosion. Exposures of layers on both sides of the distributary (Figure 9) indicate that erosion occurred possibly due to wind-driven activity. In the Saheki crater, a similar distributary with 
exposed layers and bluish clasts in the HiRISE RGB-images suggested the presence of different materials (Morgan et al., 2014). Within fan f3 of Degana-A, the HiRISE image shows bluish clasts on the distributary (Figure 9) that are possibly comparable to Saheki crater ridge. However, this part of fan $\mathrm{f} 3$ lacks mineralogical data (CRISM) to assess the composition.

The rim breaching of Degana-A crater and fan $\mathrm{f} 1$ formation is closely associated with the valleys over the eastern wall of Degana crater. In addition, the valleys that incise the outer rim of DeganaA (black arrows in Figure 10) cut through a layered wall material on the eastern side of Degana (Figure 10b). This layered material might be residual deposits from an initial fan that formed on the outer rim of Degana-A, similar to fans f5 to f9. Then, the breach through the rim produced a change in the base level of the deposits, starting to build fan f1. In this scenario, the fact that a breach formed here rather than for the other fans f5 to f9 is likely due to the large watershed (Figure 12). An important implication of this scenario is that the fans f5-f9 would have formed coevally to the fans f1 to f4 inside Degana-A crater (see section 3.5). We also identified embedded craters on the fans (Figure S2), these possibly display evidence of interbedding within the crater (Kite et al., 2017). We use observations of fan f1 to estimate the flow velocity and discharge quantitatively (see supplementary file). Following Morgan et al. (2014), we determined the value of maximum discharge as $\sim 84 \mathrm{~m}^{3} / \mathrm{s}$ (Table S1). Based on this, we also determined the supply rate of water, which is the maximum discharge per total area of source catchment, and found that the source catchment would have supplied the water at a rate of $\sim 2.25 \mathrm{~mm} / \mathrm{hr}$.

Studies on the deposition of large equatorial alluvial fans and deltas show the role of enhanced precipitation by rainfall or snow/ice melting followed by runoff (Moore and Howard, 2005; Di Achille and Hynek, 2010a,b; Armitage et al., 2011; Grant and Wilson, 2011, 2012, Wilson et al., 2021). Although many alluvial fans are evident within Degana (Figure 6), due to limited CRISM coverage, we cannot rule out hydrated mineral formation within the craters. The polygonal patterns display characteristics consistent with the patterns observed in aqueous sedimentary layers containing clay minerals that formed by contraction either from desiccation or from enhanced cold temperatures during their exhumation (Elmaarry et al., 2012; Oehler et al., 2016). The major hypotheses for polygon formation on Mars are thermal contraction and desiccation of sediments either enabled by ground ice or by sediments containing absorbed water such as in clay minerals (Neal et al., 1968; Levy et al., 2009; Elmaarry et al., 2010, 2012; Oehler et al., 2016 ). Although 
the polygons were observed on alluvial fans, which are located within the volcanic dome, we do not interpret them as lava-related cooling cracks. Polygon patterns are generally defined by four factors: shape, size, boundary type, and intersection pattern (Yoshikawa, 2003). They can be characterized by an elevated ridge boundary or a depressed trough along the boundary. The pattern of intersection can be orthogonal, random orthogonal, or random (Yoshikawa, 2003; Mangold, 2005; Oehler et al., 2016). The rectangular shape and size of the polygon in our study area form an orthogonal pattern indicative of desiccation cracks (Neal et al., 1968; Elmaarry et al., 2010, 2012; Oehler et al., 2016) and/or thermal contracted sediments, i.e., potentially ice-wedge or sandwedge polygons (Mangold, 2005; Hallet et al., 2013; Kerber et al., 2017; Brooker et al., 2018). Desiccation generally forms nested polygons that display many secondary fractures (Oehler et al., 2016). Therefore desiccation is less likely than thermal contracted ice-wedge polygons over potential periglacial terrain (Soare et al., 2014) formed by ice/snow deposition as indicated by the presence of moraines. Two types of ice-wedge polygons were suggested based on thermal stability: 1) a low centered polygon and 2) a high centered polygon (Washburn, 1980; Mackay, 2000). It was suggested that differences in their morphology potentially reflect a change in climatic conditions (Lachenbruch 1963; Mackay 2000; Jorgenson et al. 2006; Mellon et al. 2009; Abolt et al. 2018). In contrast to high-centered polygons, polygons in Figure 15c show ridges along the boundary, implying low-centered polygons. Those polygons do not have a regular shape and follow a more random geometry. They are consistent with networks of veins (also named box work deposits, Siebach and Grotzinger, 2014), which are formed by groundwater circulation and precipitations along the fractures. Their presence may imply a period of groundwater circulation during or after the alluvial fan formation period. Alternatively, another possible reason can be deposition and cementation of sand/dust in cracks formed by thermal contraction and further erosion of the material inside polygons (Oehler et al., 2016). On the other hand, the preservation of olivine-rich outcrops means that no prolonged aqueous activity took place at this location, or outcrops have been covered and therefore protected from alteration until relatively recently. Thus, the presence of alteration minerals cannot be conclusively demonstrated, but a well-developed chemical alteration seems unlikely. To decipher the fate of water-related deposits within Degana we are assuming that the crater was once covered by ice before the formation of Degana-A. With this assumption, three scenarios may explain our observations: (A) An episodic climatic warming, perhaps related to obliquity variations (e.g., Kite et al., 2017), (B) fluvial activity related to 
volcanic heat, possibly related to Alba Patera or Ceraunius Tholus (e.g., Gulick, 2001; Hauber et al., 2005; Ansan and Mangold, 2013), or (C) the role of the Degana-A impact whose heat release may have helped to melt snow and trigger fluvial activity. Scenario (A) requires to have favorable climatic warming relatively recently in the Amazonian era. This is possible according to recent studies (e.g., Kite et al., 2017), but speculative, lacking other evidence for warming, at least regionally. For instance, the older crater located in the east of Degana (Figure 3c) shows only ancient erosion by valleys, but no pristine alluvial fans as reported in Degana, while its size and wall hillslopes look quite similar. This comparison suggests that the alluvial fans formed at Degana are local. Scenario (B) is unlikely because Degana-A is far younger than the volcanic activity, and no volcanic landforms are observed inside either Degana and Degana-A craters. Regarding hypothesis (C), it has been shown that hot ejecta emplaced over an ice-rich surface could have generated local melting (Mangold, 2012; Mangold et al., 2012c; Weiss and Head, 2016) possibly explaining some of the Amazonian age fluvial activity inside craters (e.g., Williams et al., 2009). Ejecta temperatures for craters of diameter range between $5 \mathrm{~km}$ to $150 \mathrm{~km}$ were determined by Weiss and Head (2016) to be up to 490K. Snow melting due to ejecta emplacement produced by the Degana-A impact would have deposited sediments for fan $\mathrm{f} 1$. We also determined maximum and minimum values for flow velocity and discharge rate for fan $\mathrm{f} 1$ in Degana crater. The maximum value for the flow velocity is $\sim 2 \mathrm{~m} / \mathrm{s}$ whereas the discharge rate is estimated as $\sim 2.25 \mathrm{~mm} / \mathrm{hr}$. These values are lower than the estimated flow velocity and discharge rate by Kite et al. (2013) and Morgan et al. (2014). These results support our interpretation regarding snow melting and the formation of fan $\mathrm{f} 1$. The breach of the $\sim 1 \mathrm{~km}$ wide and $\sim 900 \mathrm{~m}$ high eastern rim wall of Degana-A crater also indicates the long-lasting melting of snow/ice due to Degana-A impact. At least five valleys (Figure 10a) converge around the eastern wall region of Degana-A, which might have provided sufficient sediments to breach the crater rim. Figure 12 shows the catchment area associated with these five valleys. Large catchment area (Figure 12) and positive relief of the dome lead us to envisage a high possibility of atmospheric snow/ice precipitation. This suggests that sufficient ice melt occurred to form the fan deposits within the craters. Thus, we interpret local atmospheric snow/ice precipitation as the most likely source for fluvial activity within the craters.

4.3 Geological history of the Degana crater region and its implications for the geological history of Mars 
554 The overall geologic interpretation and the sequence of events are based on stratigraphic and 555 chronological relationships. The sequence of geological events that occurred in the Degana region 556 aids in deciphering the Martian surface processes, and climatic conditions that prevailed over this 557 region. A schematic scenario is shown in Figure 17, which represents the activities that took place 558 in this region.

559 (1) Apparent model ages derived from crater size-frequency measurements by Xiao et al. (2012) 560 suggest the volcanic dome formed around $4 \mathrm{Ga}$ ago, during the Early to Mid-Noachian epochs 561 (Figure 17a).

562 (2) Degana impact crater formed on the volcanic dome and exposed the dome interior down to $\sim 2$ $563 \mathrm{~km}$. Apparent model ages suggest that Degana crater formed in the early Hesperian 3.7 Ga +0.04/5640.16 or close to the Noachian-Hesperian boundary (Figure 16b). No volcanic-origin flows were 565 observed within the crater. Therefore, we suggest that dome-related volcanic activity had ceased 566 around $3.7 \mathrm{Ga}$.

567 (3) Degana-A crater superposed Degana crater after an unknown period. It is very difficult to 568 estimate the age of Degana-A's formation because a lot of its ejecta were likely sequestered inside 569 Degana crater. Degana-A further exposed the interior of the dome or the underlying Noachian 570 crust by another $\sim 0.7 \mathrm{~km}$. In total, both craters excavated $\sim 2.7 \mathrm{~km}$ deep into the volcanic dome. 571 However, the floor of the crater is covered by four large depositional fans (Figure 6) whose 572 tentative crater retention epoch is early Amazonian.

573 (4) Multiple valleys on the wall, and floor of Degana crater, and several fan deposits within 574 Degana-A (Figures 6b,18) provide strong evidence for fluvial activity. Although the length of 575 time over which the fans formed is uncertain, we evaluate two scenarios. The orthogonal coalesced 576 alluvial fans (Figure 6b), inverted channels/distributaries, and the discharge rate for fan f1 suggest 577 that the fans were formed by steady discharges over a very long period, possibly millions of years 578 (Moore et al., 2003). We suggest that the widespread occurrence of fans within Degana required 579 snow/ice precipitation (Moore and Howard, 2005; Grant and Wilson, 2011, 2012), followed by 580 snowmelt within Degana to help the rim breaching of Degana-A. This suggests that sufficient ice 581 deposition by mantling has occurred at least since the formation of the Degana crater. On Degana582 A southern floor, possibly all the fans coalesced at their toe region and eroded (Figures 6b, 18). 583 Thus, we propose that Degana-A was affected by snow/ice cover over Degana emplaced at some 
584 point after its formation around $\sim 3.7 \mathrm{Ga}$. We infer the ejecta from Degana-A played a role in 585 melting the deposited snow/ice over the shattered dome, a scenario that had already been proposed 586 for other locations on Mars (Mangold, 2012).

587 (5) At the last stage, during the Amazonian or post fan formation (Kite et al., 2017), moraine-like 588 ridges are formed. The glacial activities in lower latitudes were reported to be more likely on the 589 pole-facing walls of the craters (Williams et al., 2009; de Haas et al., 2015). The presence of 590 moraine-like ridges on the pole facing northern wall of Degana (Figures 13, 18) provides 591 comprehensive evidence for the glacial activity that occurred up to lower mid-latitude (Shean, 592 2010). Moraine-like ridges superposed over fans f2 and f3 (Figure 13) imply their post fan 593 formation. This also suggests that the atmosphere-derived snow/ice was possible up to this latitude 594 during the Amazonian period (Figures 17, 18).

595 Overall, the major implications from our study are that the craters excavated into a Noachian 596 volcanic edifice and exposed pristine early Martian minerals, which is similar to earlier studies at 597 different location of Mars (Mustard et al., 2009; Skok et al., 2010; Quantin et al., 2012; 598 Baratoux et al., 2013). Degana crater also hosts significant evidence for post-Noachian fluvial 599 activities. This means that they formed under climatic conditions more favorable to sustain runoff, 600 which was capable to breach the Degana-A rim. Notably, no delta deposits like those formed in 601 the Jezero crater (e.g., Goudge et al., 2017) were observed in the Degana. This implies that the 602 fans in Degana-A were not deposited into a standing body of water (Fassett and Head, 2008). 603 This indicates that the climatic conditions were suited for alluvial fan deposits only which might 604 be due to limited liquid water availability due to low temperatures, lack of moisture, and/or 605 insufficient atmospheric pressure. However, this climatic condition varied over the Hesperian606 Amazonian. This suggests that during the Hesperian-Amazonian, the ice accumulation at this 607 latitude considerably reduced, which enabled moraine-forming glacial activity during the 608 Amazonian, but no more (glacio-)fluvial activity. Thus, this region is one of the locations on Mars, 609 which witnessed the transition from fan-forming fluvial activity in the Hesperian to moraine610 building glacial activity in the Amazonian.

\section{Conclusions:}


612 We carried out a detailed topographical, morphological, mineralogical, and chronological analysis 613 of impact craters Degana and Degana-A. Our results reveal the diverse geologic activities, which 614 are:

615 - Degana and Degana-A craters formed on a $\sim 1.2 \mathrm{~km}$ high Noachian volcanic dome. Both 616 impacts excavated up to $\sim 2.7 \mathrm{~km}$ deep, i.e., $\sim 1.5 \mathrm{~km}$ deep in the Noachian crust located below the base of the volcanic dome. These impacts exposed pristine Noachian mafic minerals (Mg-rich olivine and low-calcium pyroxene) on the walls of Degana-A crater. Xiao et al., 2012 mentioned that the true composition of these ancient Noachian-aged volcanoes is not known, as most of these volcanoes are heavily dust-covered and no in-situ observations were taken yet. Thus, this study provides the likely composition of one of the ancient volcanoes on Mars.

- Both crater floors are covered by depositional fans, and especially Degana-A crater fans show distinguishable ridges, stratigraphic layers, and coalesced deposits. A notable $\sim 1 \mathrm{~km}$ wide rim breach on the eastern rim of Degana-A crater and the hydrological estimation over this region suggest water flowed with a velocity of $\sim 2 \mathrm{~m} / \mathrm{s}$ and with a discharge rate of $\sim 2.25 \mathrm{~mm} / \mathrm{hr}$. This is in agreement with Kite et al., 2019 that reported a discharge rate of $3 \mathrm{~mm} / \mathrm{hr}$ for globally present channels on Mars.

- Moraine-like ridges linked to glacial activities superposed the alluvial fans. Such morainelike ridges are observed only on the pole-facing walls of Degana crater. The alluvial fan deposits and the glacial moraine ridges are non-coeval events. They strongly indicate evidence for snow/ice deposition towards the lower latitudes of Mars during HesperianAmazonian epochs suggesting local climate change on Mars. Thus, Degana is one of the important locations that report lower latitudes $\left(23^{\circ} \mathrm{S}\right)$ glacial activities on Mars (Shean, 2005).

- Based on the dome elevation, the formation of fluvial/glacial deposits within the impact craters, and the latitudinal location, we suggest atmospheric snow/ice precipitation as the possible source.

640 Hesperian-Amazonian aged fluvial and glacial deposits. 
641 Acknowledgment: We thank Hannes Bernhardt of Arizona State University and an anonymous 642 reviewer for the constructive suggestions. We thank Physical Research Laboratory, Department of 643 Space, India, for supporting our work. NM acknowledges the support from the Centre National 644 d'Etudes Spatiales (CNES), France. We thank the CRISM, HiRISE and CTX team for the 645 availability of the required datasets used in this study, which were downloaded from the PDS 646 (https://ode.rsl.wustl.edu/mars/).

647

648

\section{Figure captions:}

650 Figure 1: Location map of Degana crater, Mars. Image is MOLA DEM. a) Topographic map of 651 Degana crater and its surrounding region. b) Geologic map from Tanaka et al. (2014) indicates the 652 terrain is Noachian in age.

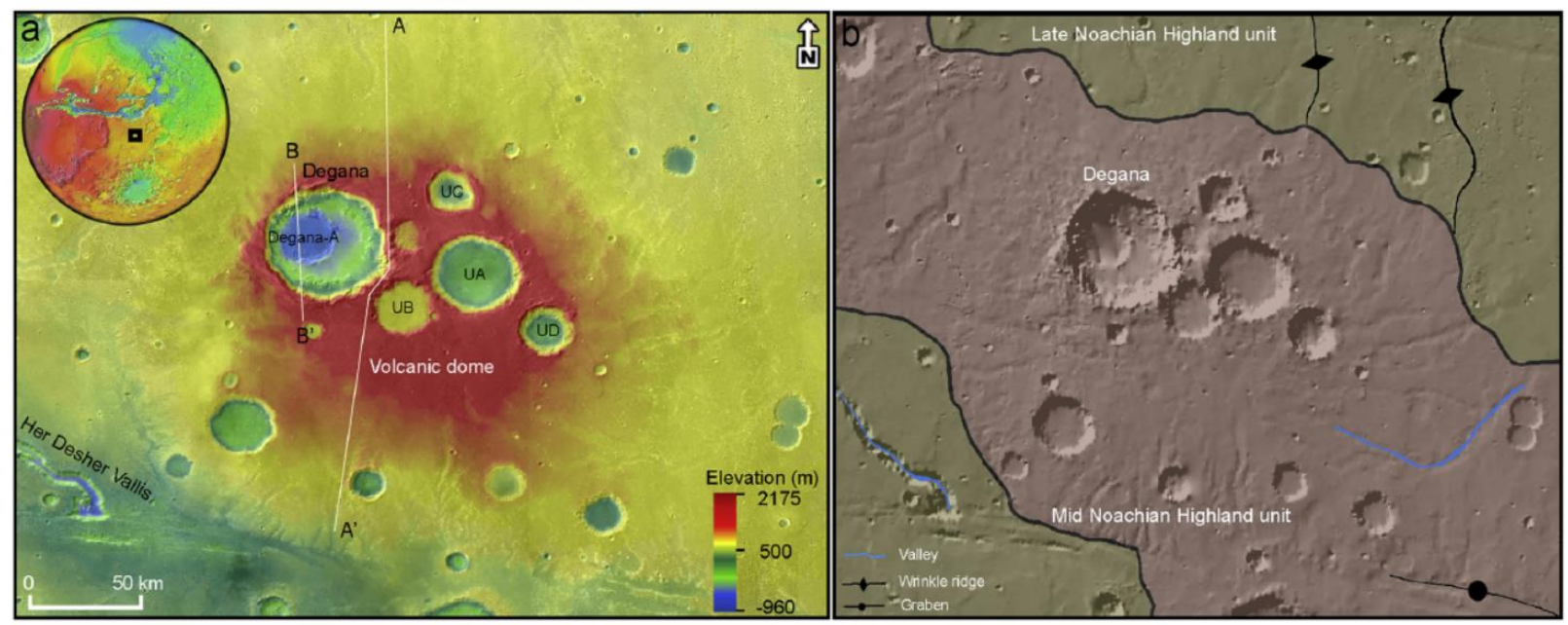


655 Figure 2: MOLA DEM-derived topographic profiles a) profile is taken across the dome, which 656 has a bell curve shape. This dome stands $\sim 1.2 \mathrm{~km}$ high from its surroundings. b) Profile taken 657 across Degana and Degana-A craters. Both impacts occurred on the dome and they have excavated $658 \sim 1.5 \mathrm{~km}$ deep material from the base of the dome. (For profiles refer to Figure 1a)
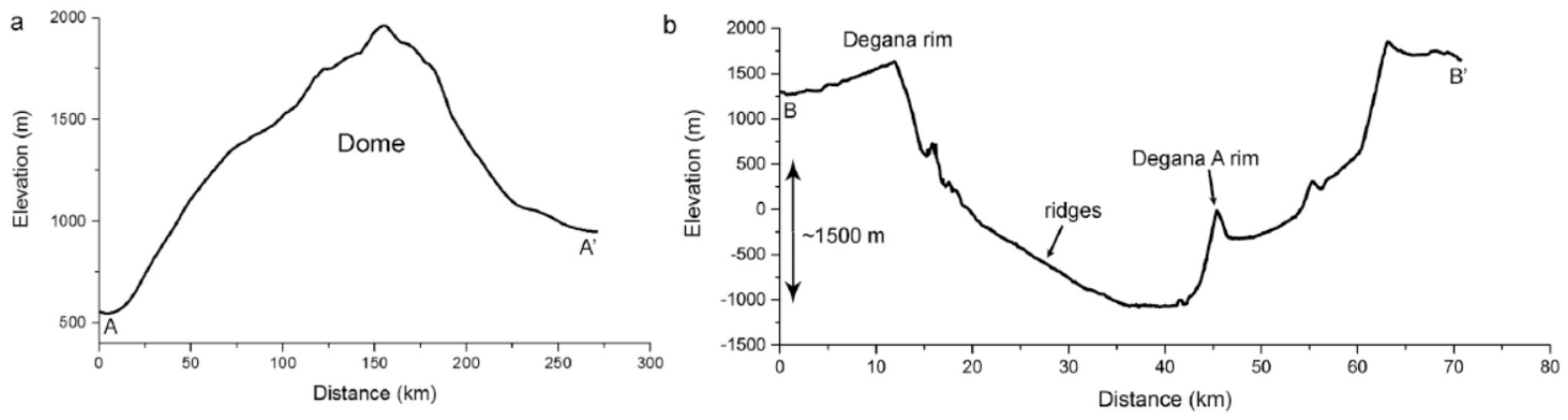
661 Figure 3: Impact craters located on top of the volcanic dome. a) Degana crater, the largest on the 662 dome. b) Degana-A crater, which superposed Degana crater. c) Unnamed crater- UA, with no 663 distinguishable ejecta. d) Unnamed crater-UB located to the southeast of Degana. e) Unnamed 664 crater-UC, with distinguishable raised rim and another smaller crater superposing its eastern wall. 665 f) Unnamed crater-UD, located at the flank of the dome. The location of all the impact craters is 666 marked in Figure 1a. (CTX mosaic by Dickson et al. (2018) is used and north is up in all the 667 images)
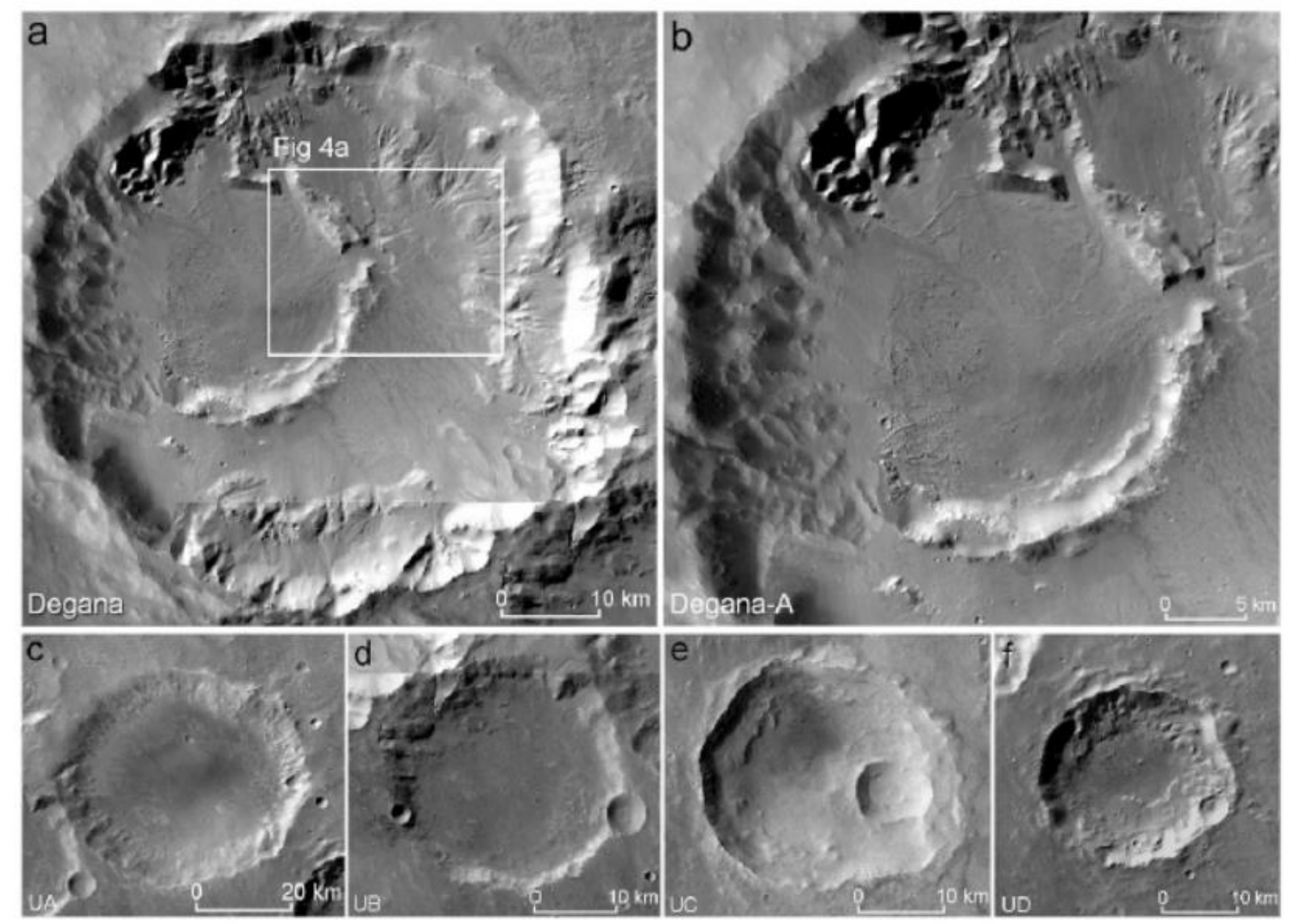

668

669

670 
671 Figure 4: a) MRO-CRISM derived summary parameters overlaid on CTX mosaic around the

672 eastern wall of Degana-A crater. Summary parameters are calculated for CRISM image

673 FRT00023F32. The summary parameter colors indicate: Red - Olivine, Cyan/green - LCP, Blue

674 - HCP (Viviano-Beck et al., 2014). b) CRISM ratioed spectra for low- Calcium pyroxene

675 identified with diagnostic $1 \mu \mathrm{m}$ and $2 \mu \mathrm{m}$ spectral features. A laboratory spectra from the RELAB

676 library is shown below for comparison. Locations P1 to P6 indicate from where the spectras are

677 extracted. c) CRISM ratioed spectra for olivine, identified with diagnostic $1 \mu \mathrm{m}$ spectral features.

678 RELAB laboratory-derived spectrum for forsterite is given below for comparison. Locations O1

679 to $\mathrm{O} 3$ indicates from where the spectras are extracted.

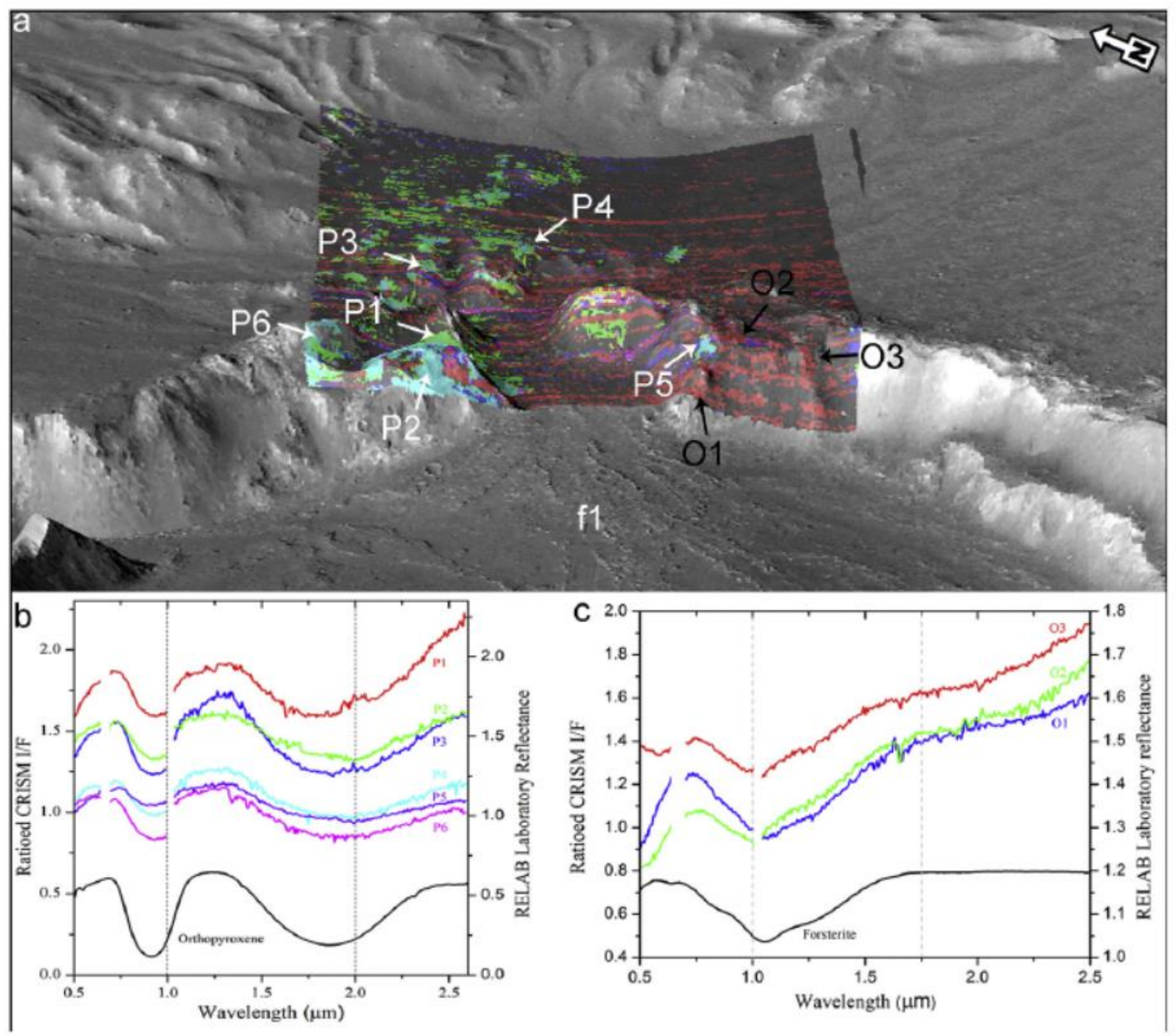


682 Figure 5: Examples of locations in HiRISE false color image for a) pyroxene on the elevated rim,

683 b) pyroxene along topmost part of the eroded valley (HiRISE ESP_026522_1560). Example 684 location for c) olivine detected along the eastern wall with light-toned exposure and d) olivine 685 signature along the eastern wall (HiRISE ESP_16540_1560).

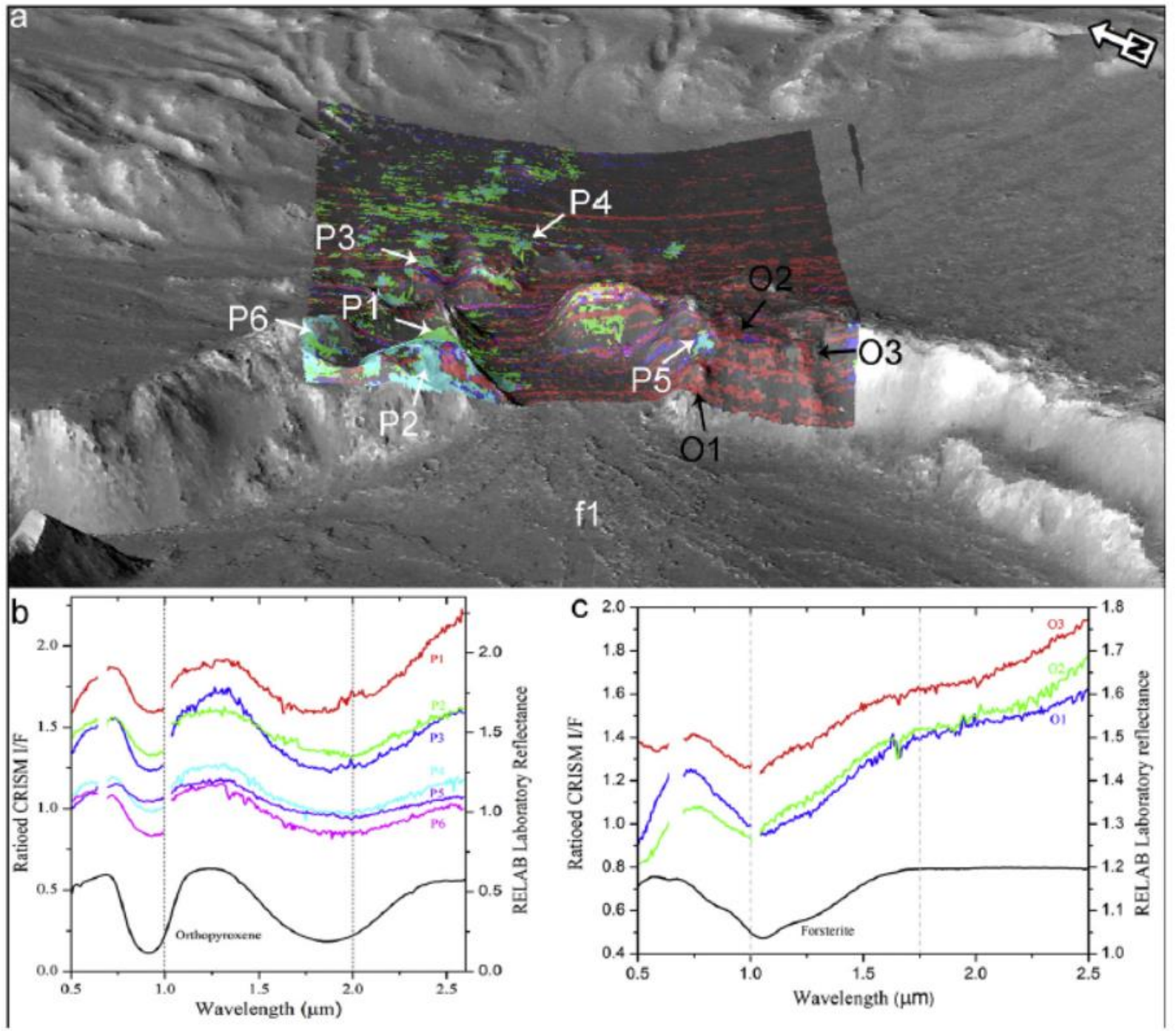


688 Figure 6: a) CTX mosaic of Degana and superposed Degana-A crater. b) Geomorphological map 689 of Degana and Degana-A craters overlaid at $80 \%$ transparency on the CTX mosaic. The 690 predominant mapped units are fan deposits, valleys over the crater rim, and moraine-like ridges.
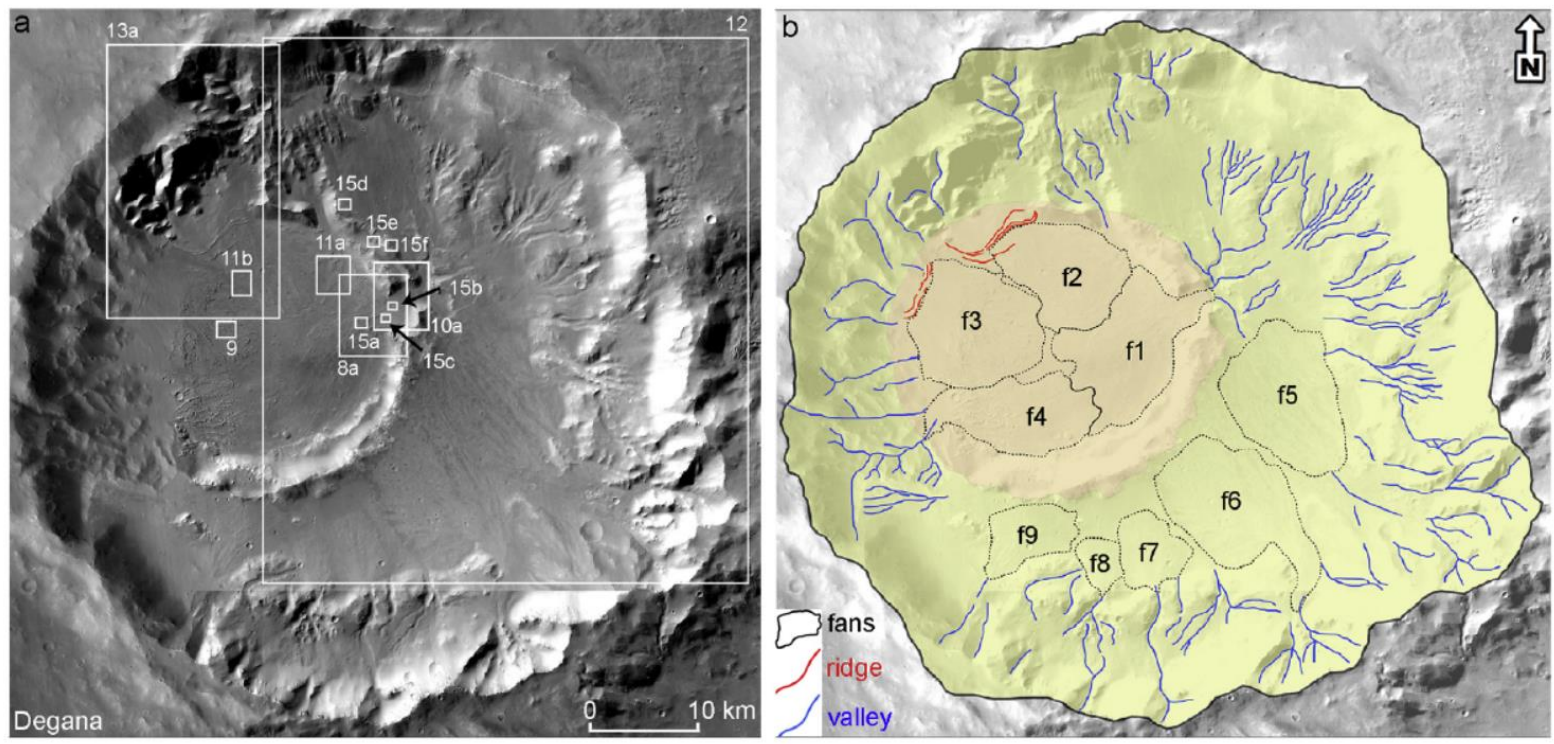
693 Figure 7: Distribution of fan deposits within Degana-A crater, a) Fan f1, located on the eastern 694 wall, whose apex region is situated on the breached rim. Individual ridges and dendritic 695 distributaries are present over the fan surface. b) Fan f2, from the northern wall. c) Fan f3 from 696 the northwestern side, with distinguishable ridges at its toe side. d) Fan $\mathrm{f} 4$ from the southwest side, 697 with deposits and distinguishable ridges. Distribution of fan deposits within Degana crater, e) Fan 698 f5, the largest fan within both craters. The toe region of this fan merges with another adjacent small 699 fan deposit. f) Fan f6, from the southeastern wall with broad fan-shaped deposits at the toe region. 700 The toe region of the fan deposits terminated at the walls of Degana-A crater. Colored lines over 701 the fans indicate the traverses of topographic profile Figure S3, White arrows - distinguishable 702 distributaries over the fans. (CTX IDs a-d: G02_018874_1561_XN_23S045W, and e-f: 703 D19_034592_1579_XN_22S045W)

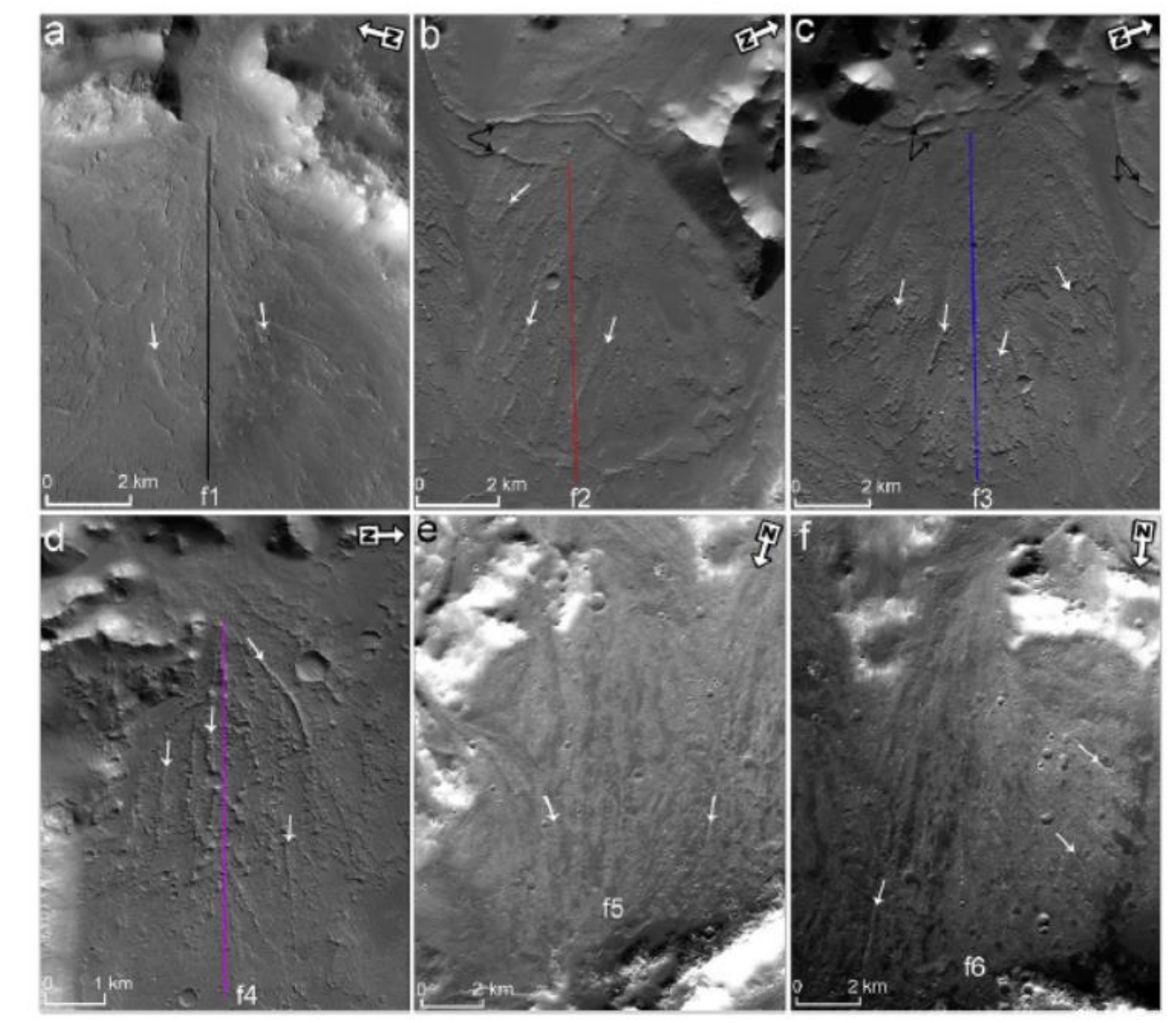


Figure 8: a) HiRISE stereo pair (ESP_016540_1560 and ESP_016039_1560) derived DEM image for fan f1. b) Elevation profile (AA') taken along a discontinuous distributary ridge, note the height

708 variation within the ridge c) HiRISE false-color image shows some parts of the discontinuous 709 ridge. At the downslope side, crosscutting ridges are observed with exposed stratigraphic deposits 710 (HiRISE ID: ESP_016540_1560). This false-color image also highlights the multiple 711 distinguishable layers within the fan deposits. The black arrows display the locations marked on 712 the elevation profile in Figure 7b. d) HiRISE false-color image (ESP_016540_1560) over the toe 713 region of fan $\mathrm{f} 1$. The eroded ridges expose multiple stratigraphic layers located at different 714 elevations (marked by white arrow). These layers likely hint at multiple stages of deposition within 715 Degana-A crater. (White dot shows elevation value at that particular location.)

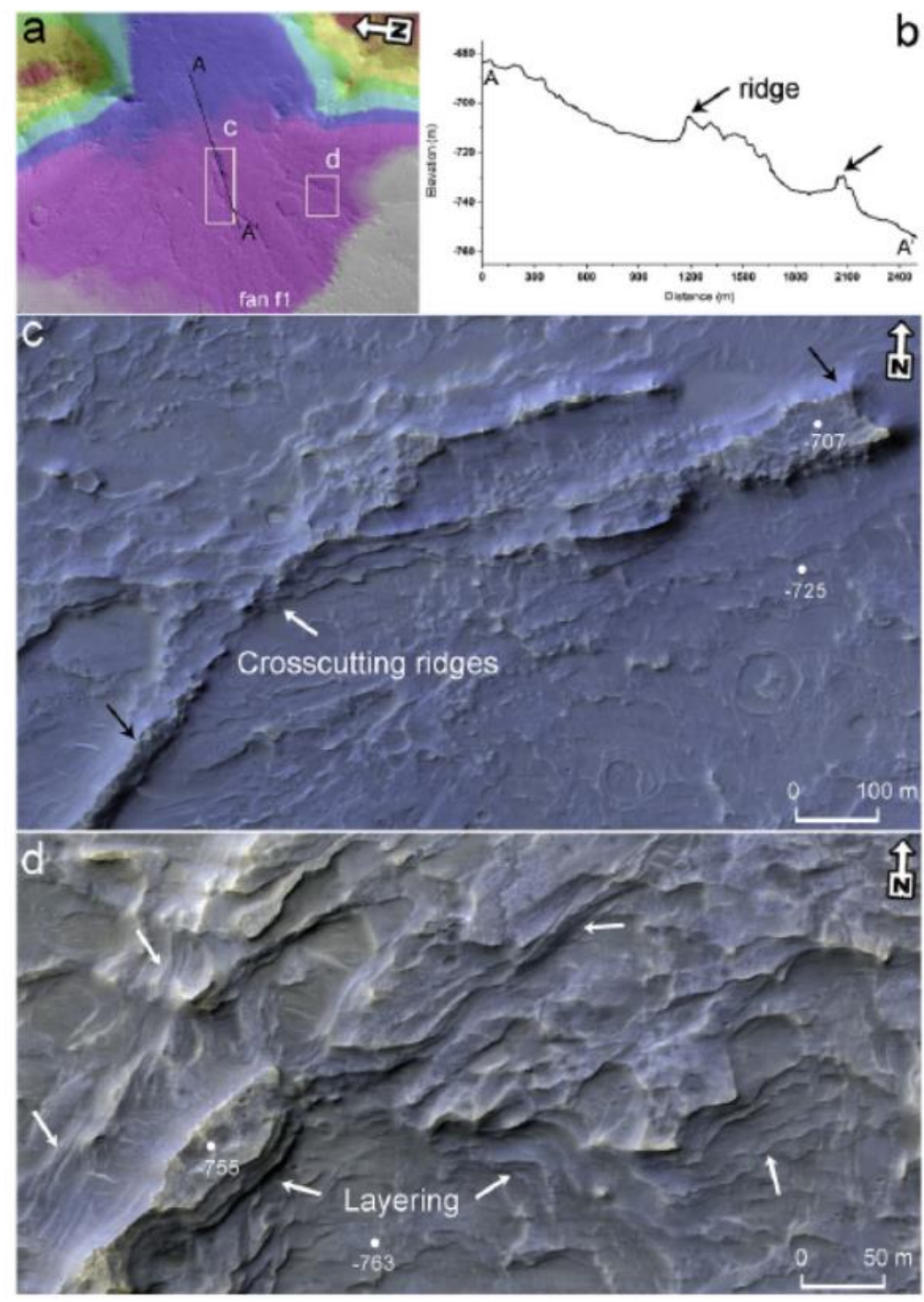


717 Figure 9: HiRISE color image ESP_018874_1560 reveals details of ridges with interbedded fine 718 sediments and exposed stratigraphy. The layers are exposed all around the ridge and they are 719 individually distinguishable. The ridge is surrounded by aeolian deposits, TARs, and mantled by 720 dust showcasing the role of wind in eroding the ridge and exposing layers. Towards the toe side 721 of the ridge, it is narrow and exposed more distinct light-toned layers, which are $\sim 3-5 \mathrm{~m}$ thick.

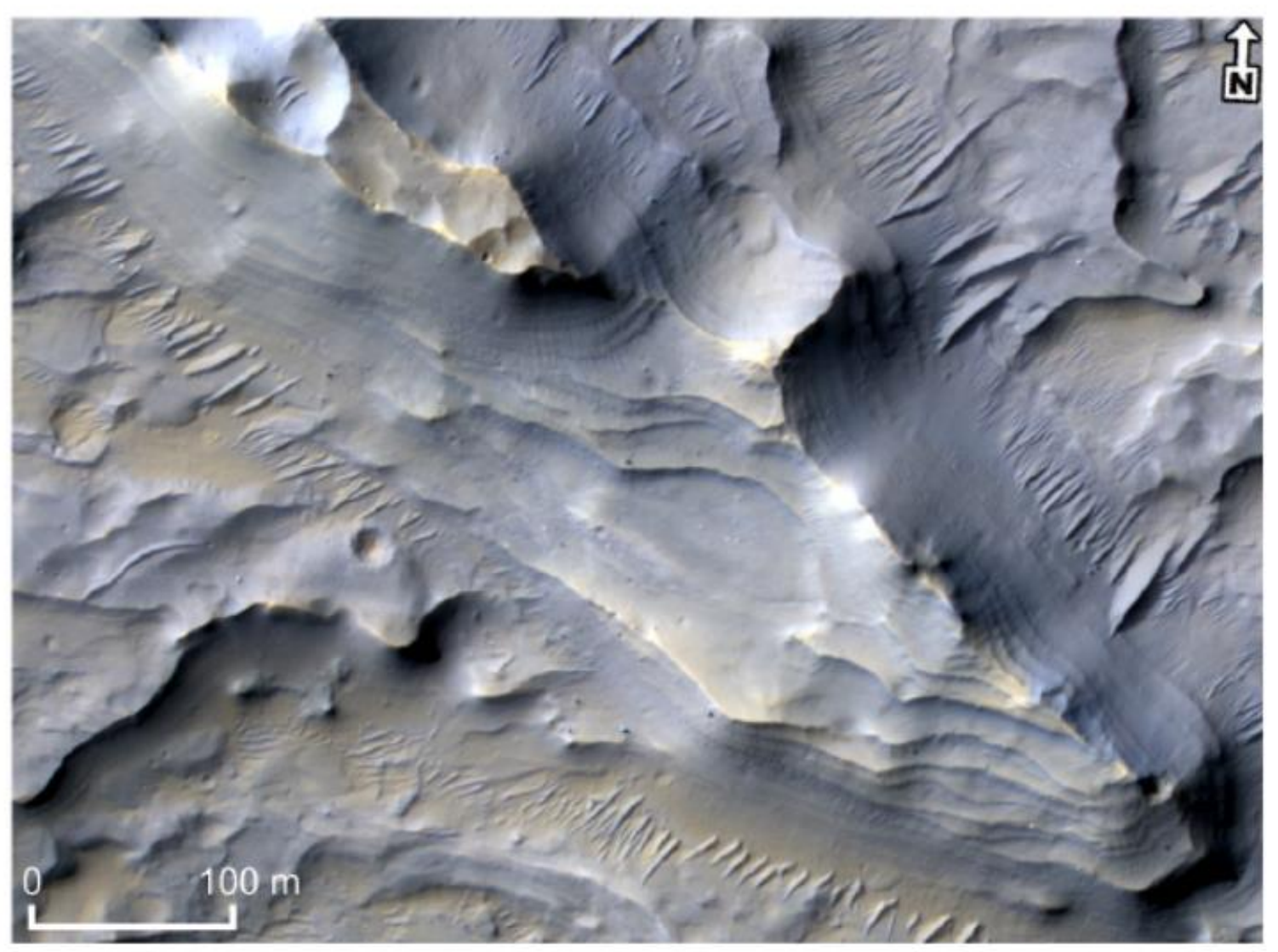


724 Figure 10: a) The apex region of fan f1 located over the breached rim region of Degana-A.

725 Towards the north, the rim height is $\sim 800 \mathrm{~m}$, whereas, towards the south, it is much higher at $\sim 920$

$726 \mathrm{~m}$. This suggests that the $\sim 900 \mathrm{~m}$ high and $\sim 1 \mathrm{~km}$ wide rim is breached by fan $\mathrm{f} 1 \mathrm{deposits}$. Over

727 this part, nearly five valleys from the Degana crater wall converge, which suggests the possible

728 source for the rim breaching. Black arrows display the valleys, which fed fan f1. b) HiRISE color 729 image ESP_026522_1560_COLOR of one of the eroded walls of the valley shows distinguishable 730 layers. We interpret this exposed stratigraphy as earlier deposits within the Degana eastern wall, 731 which later got breached by the valley associated with the rim breaching.

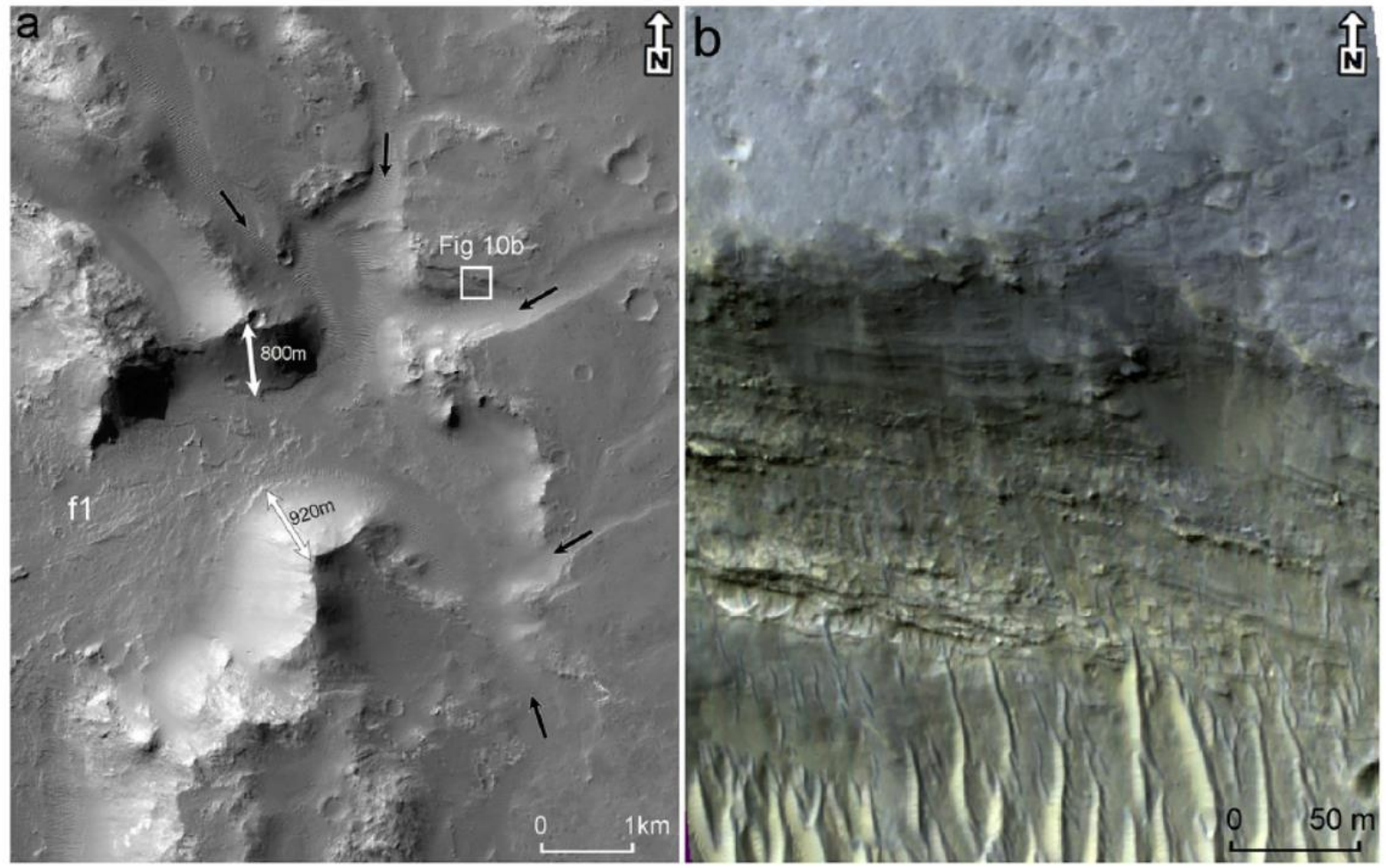


734 Figure 11: Example locations of intersecting fan deposits within Degana-A crater. a) Region of 735 convergence of fan $\mathrm{f} 1$ and $\mathrm{f} 2$, with marked distributaries (black arrow, aligned in the direction of 736 the fan). Layers were identified at the front scarp of both the fans. The hummocky patch located 737 at the termini region of both the fans ( $\mathrm{f} 1$ and $\mathrm{f} 2$ ) is $20 \mathrm{~m}$ elevated. On both sides of this hummocky 738 surface, the fan deposits expose the layers at their front scarp (HiRISE ID ESP_016039_1560 and 739 ESP_035159_1560). b) Region of convergence between fan f2 and f3, with marked distributaries 740 (black arrows, aligned in the direction of the fan). Layers were identified at the termini region of 741 fan f2. The dust mantled the trough in between the fan deposits. The orientation of both fan 742 deposits are different, which crosscut/superpose each other nearly orthogonal (HiRISE ID 743 ESP_018874_1560).

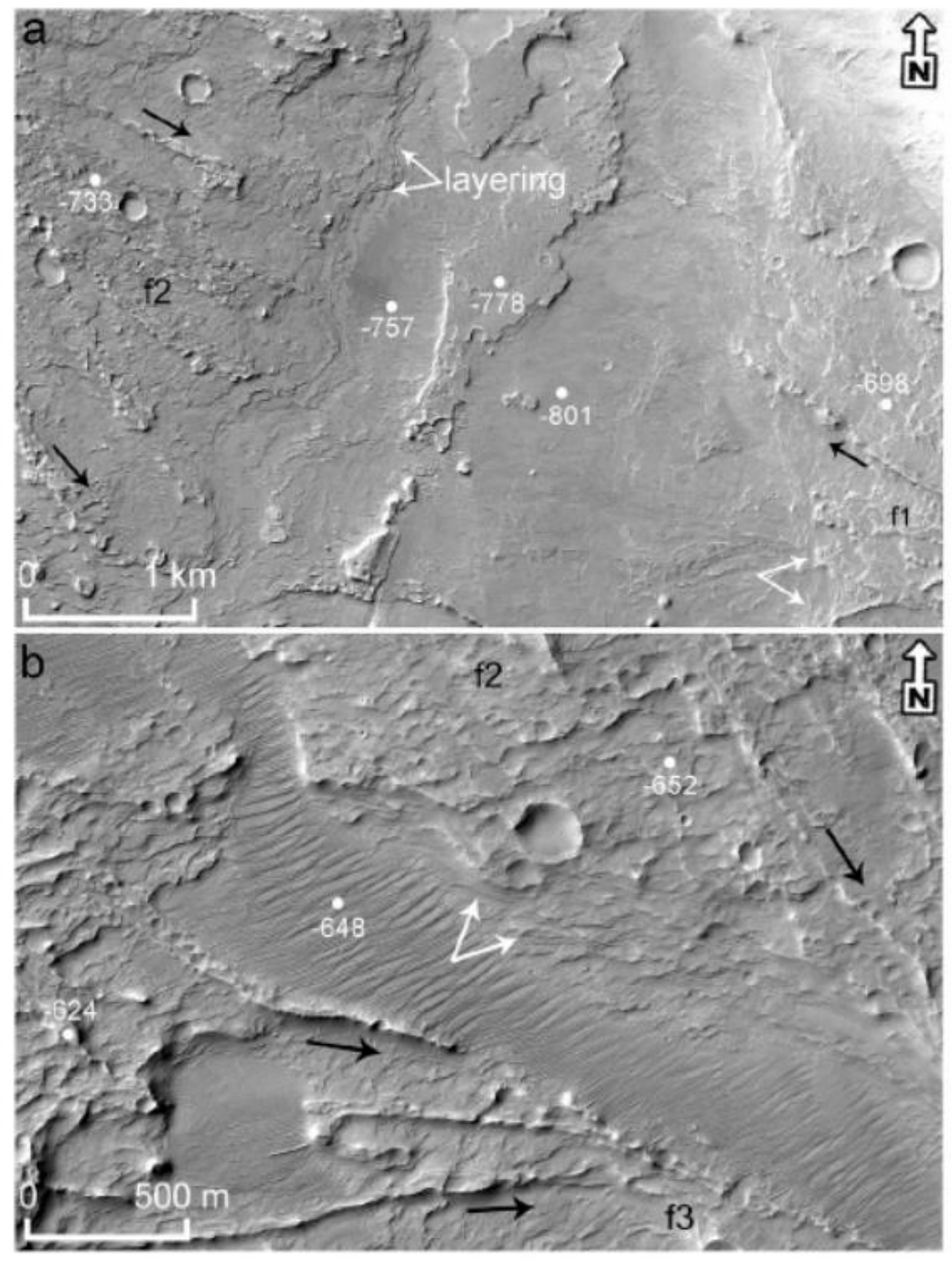


Figure 12: MGS MOLA- MEX HRSC blended DEM overlaid on the CTX image in the eastern

747 side of Degana crater. This part is the possible catchment area for the five valleys, which played a

748 role in breaching the Degana-A eastern rim. The elevation of the catchment area ranges from -511

749 to $2087 \mathrm{~m}$. The boundary of fan $\mathrm{f} 1$ is marked with a dotted gray line. The estimated catchment area

750 is larger in comparison to the area of fan $\mathrm{fl}$.

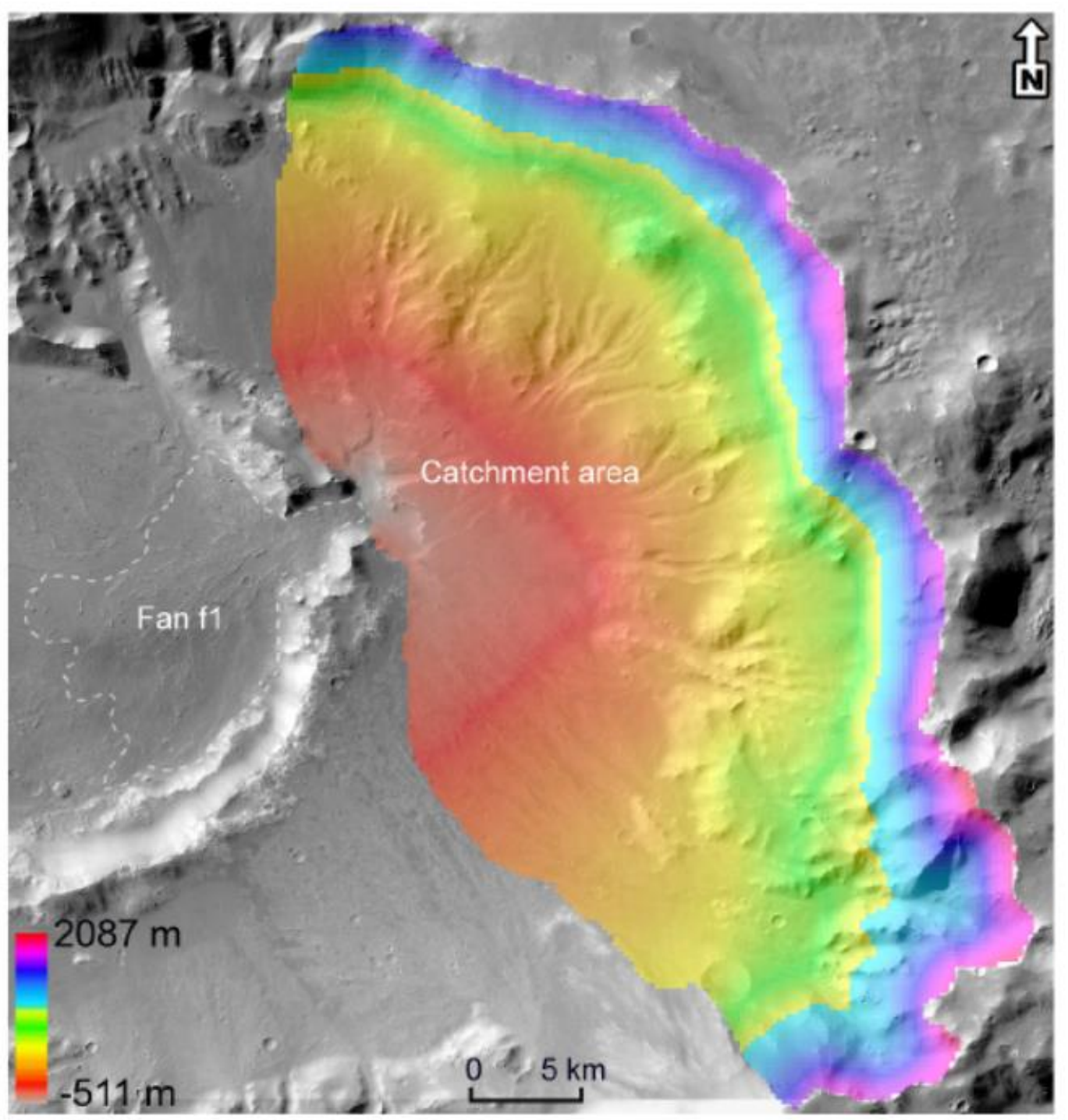


753 Figure 13: a) CTX image (G02_018874_1561_XN_23S045W) of the northern wall of Degana 754 crater showing moraine-like ridges (marked with black arrow). These moraine-like ridges occur 755 on the pole-facing wall. These ridges superposed over two fan deposits (f2 and f3). b) four 756 distinguishable moraine-like ridges formed on fan $\mathrm{f} 2$. The thickness and the relative height of the 757 ridges vary.

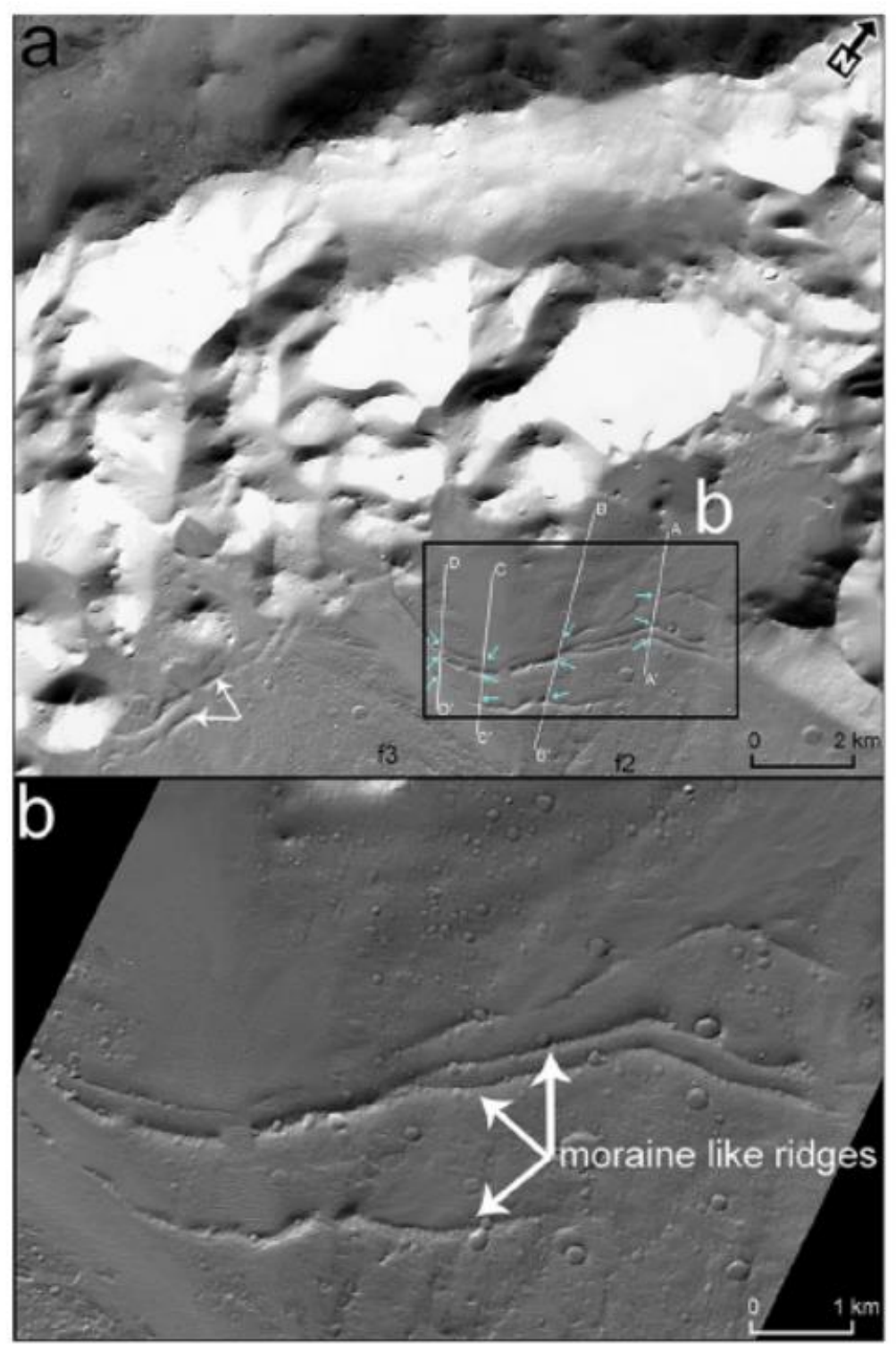


760 Figure 14: Example elevation profiles used to determine the thickness of moraine-like ridges 761 extracted from CTX DEM (stereo-pair CTX_016540_1579_034592_1579). Red is the location of 762 ridges. The height of some of the ridges is unresolvable in the CTX DEM.
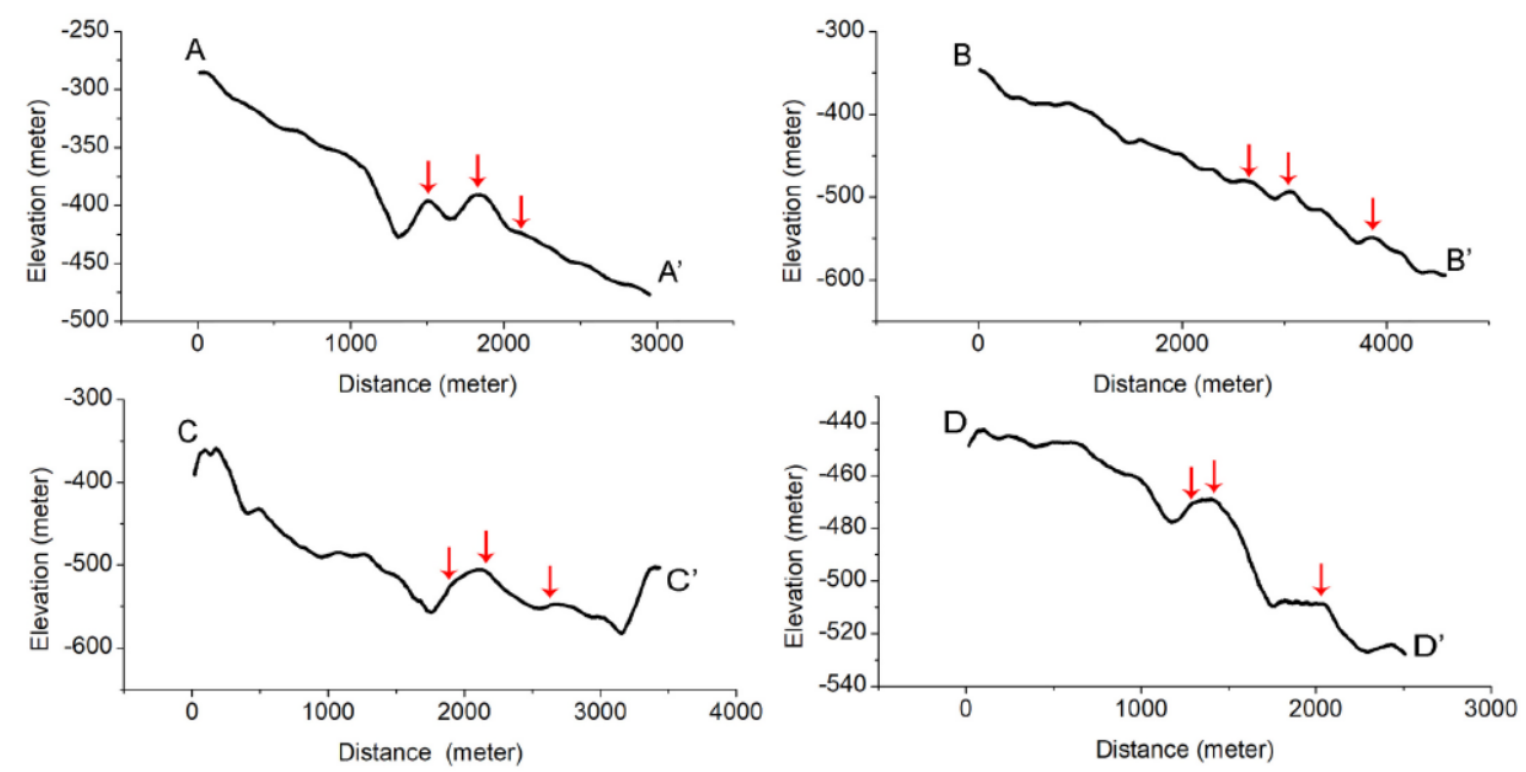

763

764 
765 Figure 15: Examples of polygons within the Degana-A fan deposits. a) Trough boundary type 766 polygons on fan f1. b) Polygons formed over the layered ridges. The size and extent of the 767 polygons vary around the ridge. c) Ridge boundary type polygon with hollows at the center and 768 raised ridges at the boundaries. Examples of polygons within the walls of Degana crater. d) 769 Polygons over the raised northern outer wall (OW) of Degana-A crater with varying sizes. e) 770 Polygons with dust mantling over the OW of Degana-A crater. f) Polygons on the inner walls (IW) 771 of Degana crater. All the polygons on the walls are observed along the topmost part of the rim 772 only. (HiRISE ID ESP_016540_1560).

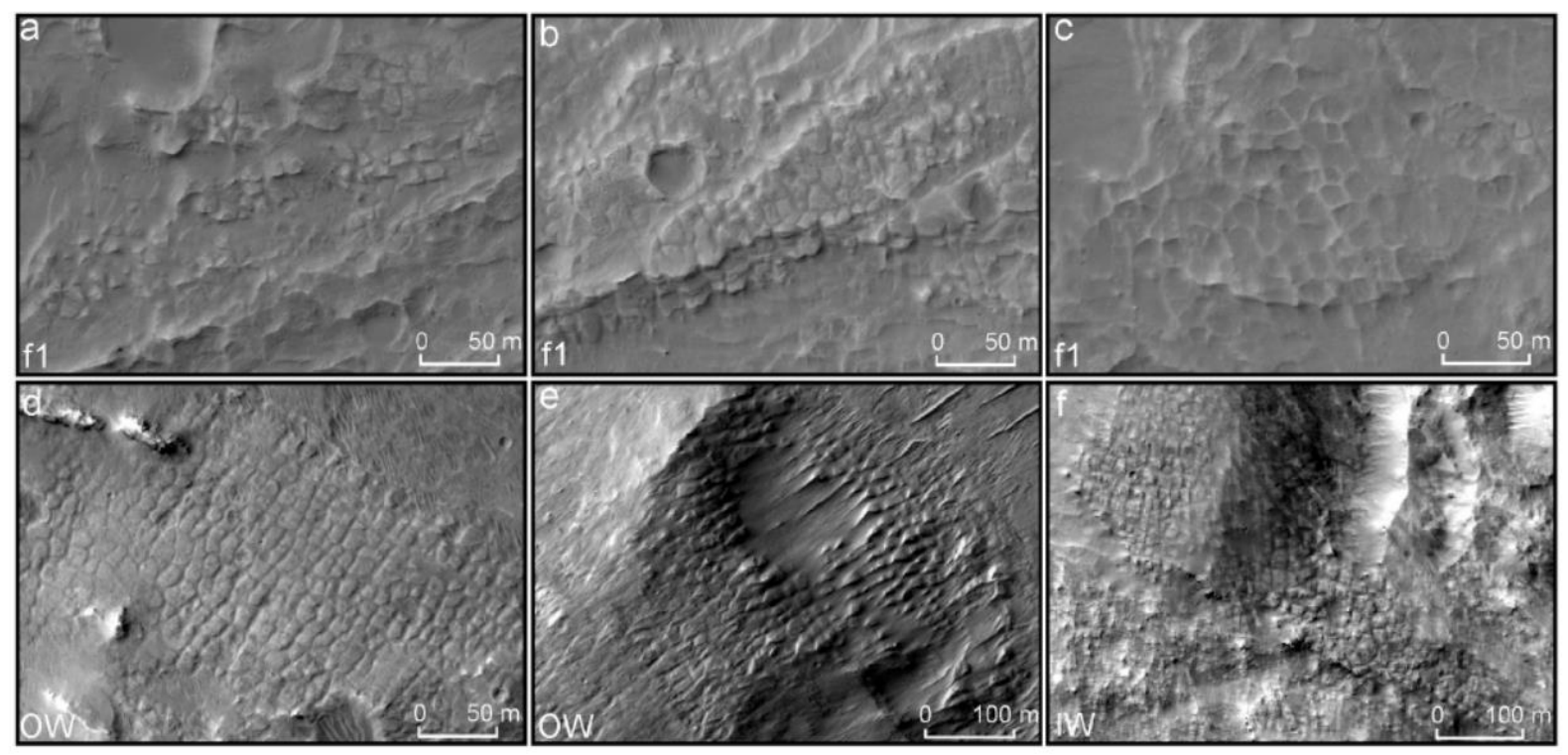


775 Figure 16: a) Degana crater and its ejecta boundary with superposed craters considered for crater 776 chronology. Counts (red circles) were conducted using CTX images. b) Relative ages were 777 determined using the production function of Ivanov (2001) and chronology function of Hartmann 778 and Neukum (2001). The apparent model age of Degana crater is $\sim 3.7$ Gyr. c) Cumulative crater 779 size-frequency distribution for all the fans within both craters. d) Differential crater size-frequency 780 distribution for all the fans within both craters.
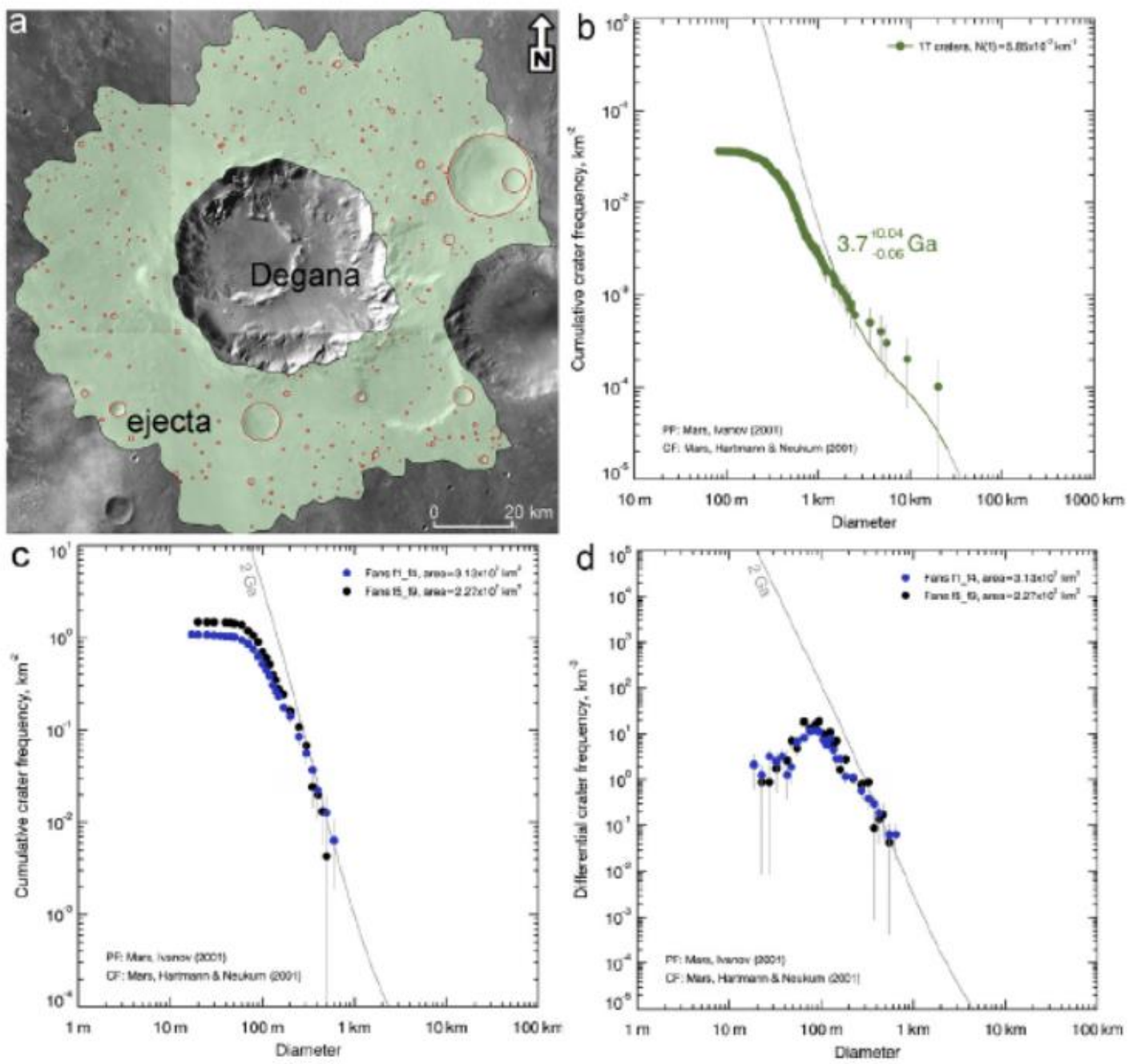

781 
783 Figure 17: Schematic perspective outlining the tentative sequence of events. a) Volcanic dome 784 formation at $\sim 4.0 \mathrm{Ga}$ with an elevation of $\sim 1.2 \mathrm{~km}$ above the surrounding surface (baseline of the 785 dome). b) Formation of Degana crater at $\sim 3.7 \mathrm{Ga}$ excavating $\sim 2 \mathrm{~km}$ of the volcanic dome. c) 786 Formation of Degana-A in Degana crater and additional $\sim 0.7 \mathrm{~km}$ of excavation. In total, both the 787 craters excavate $\sim 2.7 \mathrm{~km}$. The crater size-frequency distribution for all the fans suggests an 788 Amazonian crater retention age.
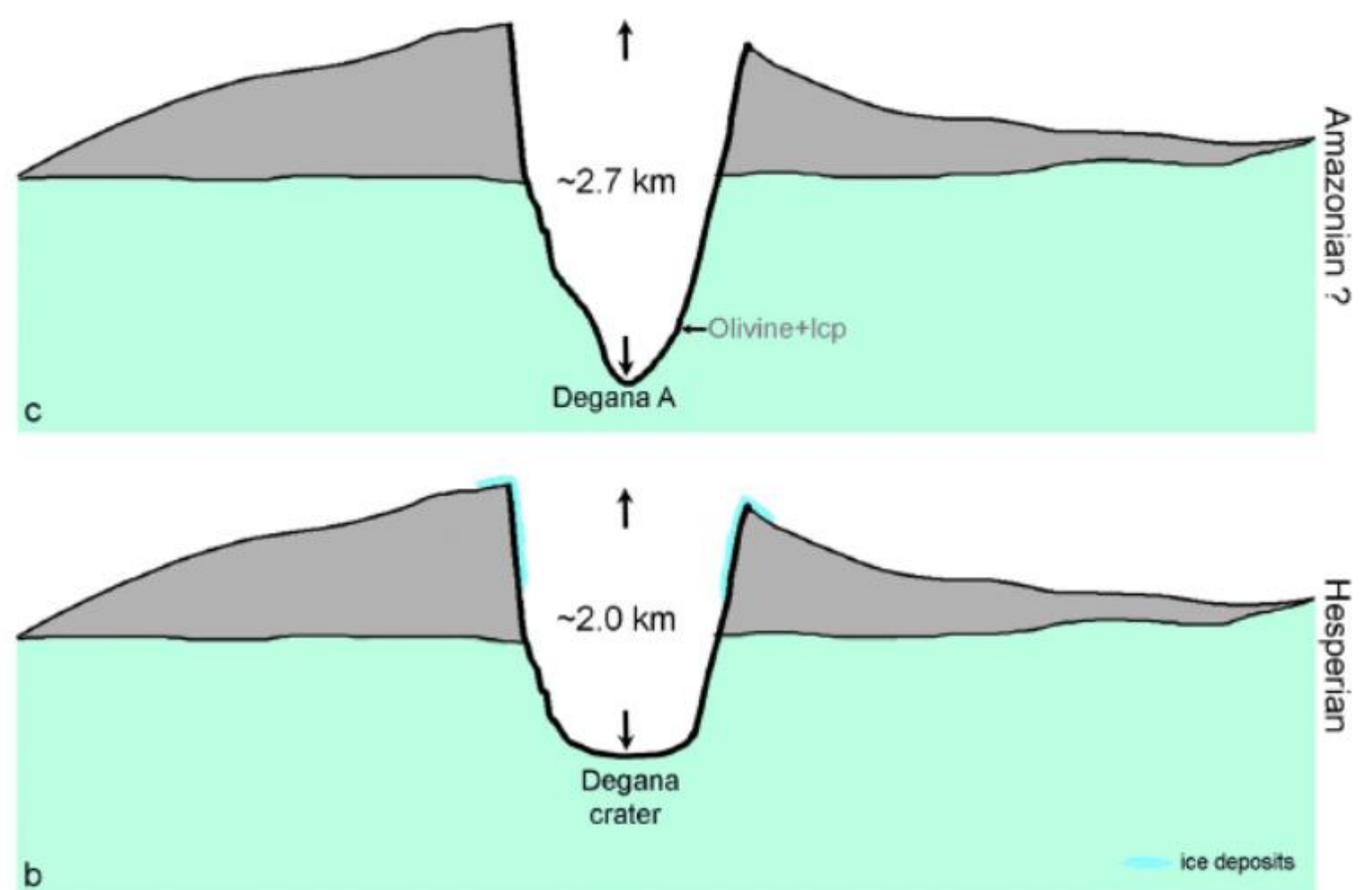

b

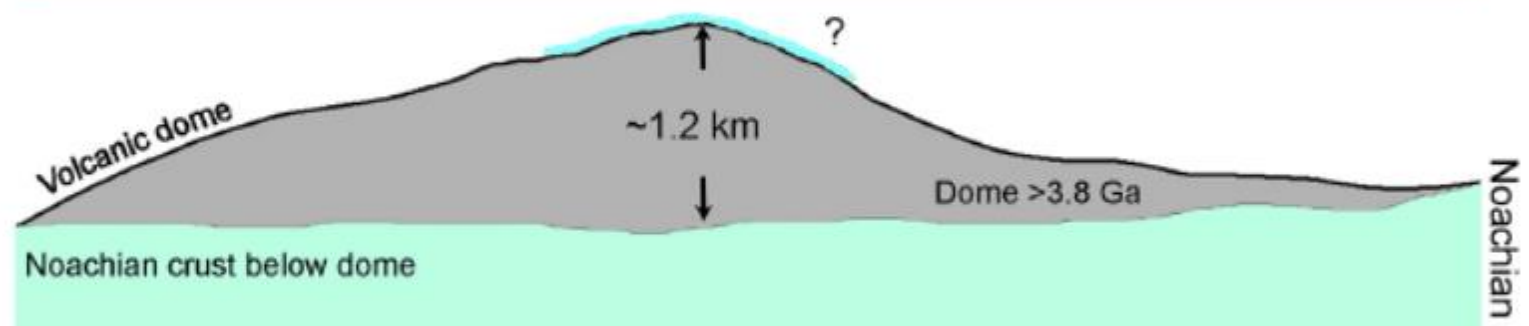


Figure 18: Schematic diagram of the current state of Degana and Degana-A. Locations of mafic minerals, fluvial and glacial landforms are marked within the exposed surface.

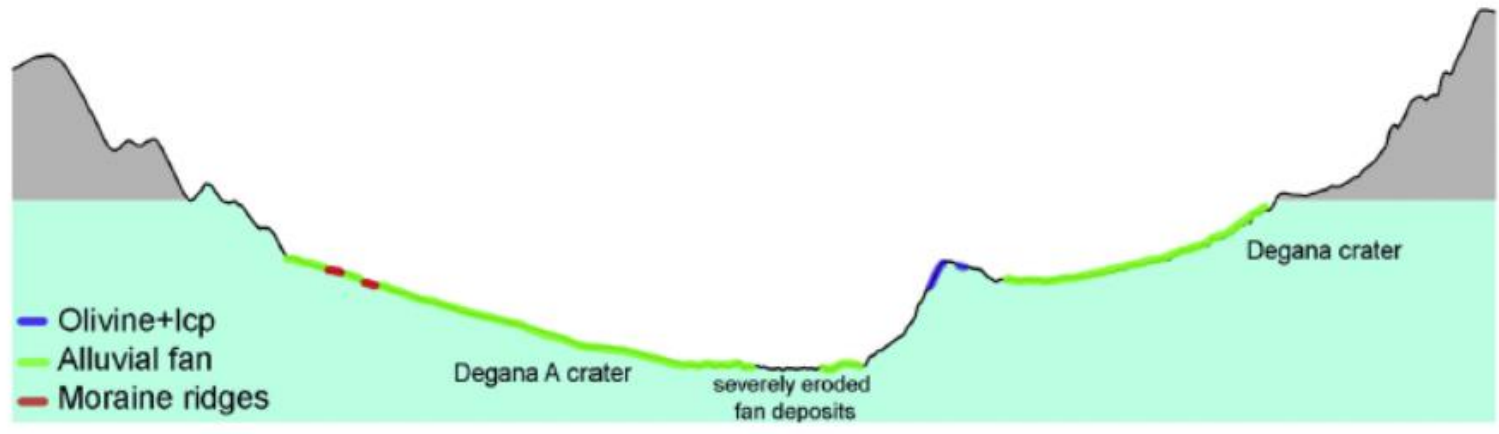

Supplementary Figure S1: MGM map prepared using CRISM image FRT00023F32. The scale 796 has been adjusted to convey the differences. The MGM map shows that the region is enriched in LCP.

Supplementary Figure S2: Example of embedded craters identified on Degana-A crater fan deposits (HiRISE ID: ESP_035159_1560 (a), ESP_018874_1560 (b,d), ESP_016540_1560 (c)).

Supplementary Figure S3: CTX DEM-derived elevation profiles taken along the major axis of 801 four fans (f1-f4, Figure 7a-d) located within Degana-A crater.

Tables:

804 Table 1: Details of center pixel and the number of pixels used for the spectra shown in figure $4 b, c$.

\begin{tabular}{|l|l|l|}
\hline Labels & Center Pixel/Pixels & $\begin{array}{l}\text { Num } \\
\text { ber of } \\
\text { Pixels }\end{array}$ \\
\hline Figure 4b & & \\
\hline P1 (numerator); (denominator) & $\mathrm{X}: 551, \mathrm{Y}: 344 ; \mathrm{X}: 551, \mathrm{Y}: 301$ & $5 * 5$ \\
\hline P2 (numerator); (denominator) & $\mathrm{X}: 370, \mathrm{Y}: 358 ; \mathrm{X}: 370, \mathrm{Y}: 149$ & $3 * 3$ \\
\hline P3 (numerator); (denominator) & $\mathrm{X}: 575, \mathrm{Y}: 338 ; \mathrm{X}: 575, \mathrm{Y}: 282$ & $5^{* 5}$ \\
\hline P4 (numerator); (denominator) & $\mathrm{X}: 323, \mathrm{Y}: 283 ; \mathrm{X}: 323, \mathrm{Y}: 96$ & $3 * 2$ \\
\hline P5 (numerator); (denominator) & $\mathrm{X}: 581, \mathrm{Y}: 101 ; \mathrm{X}: 581, \mathrm{Y}: 83$ & $3 * 3$ \\
\hline P6 (numerator); (denominator) & $\mathrm{X}: 524, \mathrm{Y}: 410 ; \mathrm{X}: 524, \mathrm{Y}: 100$ & $5 * 5$ \\
\hline
\end{tabular}




\begin{tabular}{|l|l|l|}
\hline Figure 4c & & \\
\hline O1 (numerator); (denominator) & $\mathrm{X}: 615, \mathrm{Y}: 117 ; \mathrm{X}: 615, \mathrm{Y}: 10$ & $6 * 3$ \\
\hline O2 (numerator); (denominator) & $\mathrm{X}: 547, \mathrm{Y}: 99 ; \mathrm{X}: 547, \mathrm{Y}: 8$ & $5 * 5$ \\
\hline O3 (numerator); (denominator) & $\mathrm{X}: 581, \mathrm{Y}: 42 ; \mathrm{X}: 581, \mathrm{Y}: 12$ & $9 * 7$ \\
\hline
\end{tabular}

805

806 Table 2: Details of all the fans mapped within Degana crater with length, area, and slope.

\begin{tabular}{|c|c|c|l|}
\hline Fan Name & $\begin{array}{l}\text { Approx. Fan length (along } \\
\text { major axis) }(\mathrm{in} \mathrm{km)}\end{array}$ & $\begin{array}{l}\text { Approx. Area } \\
\left(\mathrm{in} \mathrm{km}^{2}\right)\end{array}$ & $\begin{array}{l}\text { Slope } \\
\text { (degrees) }\end{array}$ \\
\hline $\mathrm{f} 1$ & 13.39 & 70.06 & 2.62 \\
\hline $\mathrm{f} 2$ & 9.09 & 60.36 & 2.47 \\
\hline $\mathrm{f} 3$ & 10.21 & 76.00 & 2.71 \\
\hline $\mathrm{f} 4$ & 10.10 & 52.11 & 3.81 \\
\hline $\mathrm{f} 5$ & 11.10 & 79.22 & 2.32 \\
\hline $\mathrm{f6}$ & 11.98 & 85.05 & 2.50 \\
\hline $\mathrm{f7}$ & 5.67 & 25.65 & 2.98 \\
\hline f8 & 4.22 & 10.11 & 2.75 \\
\hline f9 & 7.63 & 27.44 & 2.59 \\
\hline
\end{tabular}

807

808

809 Table 3: Geometric characteristics of moraine-like ridges on the northern wall of Degana-A.

\begin{tabular}{|l|l|l|l|}
\hline Profile ID & $\begin{array}{l}\text { Maximum height of } \\
\text { moraine-like ridges }(\mathrm{m})\end{array}$ & $\begin{array}{l}\text { Slope (in degrees) } \\
\alpha\end{array}$ & $\begin{array}{l}\text { Basal stress/density } \\
\left(\mathrm{m}^{2} / \mathrm{s}^{2}\right)\end{array}$ \\
\hline $\mathrm{AA}^{\prime}$ & 20 & 3.49 & 4.5 \\
\hline $\mathrm{BB}^{\prime}$ & 8 & 3.0 & 1.6 \\
\hline $\mathrm{CC}^{\prime}$ & 51 & 2.74 & 9.1 \\
\hline $\mathrm{DD}^{\prime}$ & 8 & 2.24 & 1.2 \\
\hline Average & 22 & & 4.1 \\
\hline
\end{tabular}

810

\section{References}


812 Abolt, C. J., Young, M. H., Atchley, A. L., and Harp, D. R., 2018. Microtopographic control on 813 the ground thermal regime in ice-wedge polygons. The Cryosphere, 12, 1957-1968, 814 https://doi.org/10.5194/tc-12-1957-2018.

815 Adams, J. B., 1974. Visible and near-infrared diffuse reflectance: Spectra of pyroxenes as applied 816 to remote sensing of solid objects in the Solar System. J. Geophys. Res., 79, 4829-4836, 817 DOI:10.1029/JB079i032p04829.

818 Ansan, V., and Mangold, N., 2013. 3D morphometry of valley networks on Mars from 819 HRSC/MEX DEMs: Implications for climatic evolutionthrough time. Journal of Geophysical 820 Research: Planets,118, 1873-1894. https://doi.org/10.1002/jgre.20117.

821 Arfstrom, J., and Hartmann, W. K., 2005. Martian flow features, moraine-like ridges, and gullies: 822 Terrestrial analogs and interrelationships. Icarus, $174 \quad$ (2), $321-\quad 335$. 823 https://doi.org/10.1016/j.icarus.2004.05.026

824 Armitage, J. J., Warner, N. H., Goddard, K., and Gupta, S., 2011. Timescales of alluvial fan 825 development by precipitation on Mars. Geophys. Res. Lett., 38, L17203, 826 DOI:10.1029/2011GL048907

827 Baratoux, D., Toplis, M. J., Monnereau, M., and Sautter, V., 2013. The petrological expression of 828 early Mars volcanism. J. Geophys. Res. Planets,118, 59-64, DOI:10.1029/2012JE004234.

829 Berman, D. C., Balme, M. R., Rafkin, S. C. R., and Zimbelman, J.R., 2011. Transverse Aeolian 830 Ridges (TARs) on Mars II: Distributions, orientations, and ages. Icarus, 213, 116- 130, 831 doi:10.1016/j.icarus.2011.02.014.

832 Blair, T.C. and McPherson, J.G., 1994. Alluvial fans and their natural distinction from rivers based 833 on morphology, hydraulic processes, sedimentary processes, and facies assemblages. Journal of 834 sedimentary research, 64(3a), pp. 450-489.

835 Blair, T.C., and McPherson, J.G., 2009. Processes and forms of alluvial fans. In: Parsons, A.J., 836 Abrahams, A.D. (Eds.), Geomorphology of Desert Environments. Springer Science+Business 837 Media B.V., pp. 413-466. 
Boatwright, B. D., \& Head, J. W. 2019. Fluvial Geology of the Northwest Hellas Region, Mars: Evidence for Localized Drainage and Terrain Inversion. In Lunar and Planetary Science Conference (p. 2688).

Brooker, L. M. et al., 2018. Clastic Polygonal Networks Around Lyot Crater, Mars: Possible Formation Mechanisms from Morphometric Analysis. Icarus, 302, 386 - 406.

Bristow, T. F., Rampe, E. B., Achilles, C. N., Blake, D. F., Chipera, S. J., Craig, P., et al., 2018. Clay mineral diversity and abundance in sedimentary rocks of Gale crater, Mars. Science Advances, 4(6), eaar3330. https://doi.org/10.1126/sciadv.aar3330.

Burns, R. G., 1970. Crystal field spectra and evidence of cation ordering in olivine minerals. American Mineralogist, 55, 1608-1632.

Carter, J. et al., 2013. Hydrous minerals on Mars as seen by the CRISM and OMEGA imaging spectrometers: Updated global view. J. Geophys. Res. (Planets), 118 (2013), pp. 831-858

Clenet, H., Pinet, P. C., Daydou, Y., Heuripeau, F., Rosemberg, C., Baratoux, D., and Chevrel, S., 2011. A new systematic approach using the Modified Gaussian Model: Insight for the characterization of chemical composition of olivines, pyroxenes, and olivine-pyroxene mixtures. Icarus, 213, 404-422, DOI:10.1016/j.icarus.2011.03.002.

Cloutis, E. A., Galley, M. J., Jackowski, T. L., and Reed, R. L., 1986. Calibrations of phase abundance, composition, and particle size distributions for olivine-orthopyroxene mixtures from reflectance spectra. J. Geophys. Res., 91, 11,641-11,653, DOI:10.1029/JB091iB11p11641.

Cloutis, E. A., and Gaffey, M. J., 1991. Pyroxene spectroscopy revisited: Spectral composition correlations and relationship to geothermometry. J. Geophys. Res., 96, 22,809-22,826, DOI:10.1029/91JE02512.

Costa, J.E., 1988. Rheologic, geomorphic, and sedimentologic differentiation of water floods, hyper-concentrated flows, and debris flows. In: Baker, V.R. et al. (Eds.), Flood Geomorphology. Wiley-Interscience, pp. 113-122.

Crosta, G.B. and Frattini, P., 2004. Controls on modern alluvial fan processes in the central Alps, northern Italy. Earth Surface Processes and Landforms, 29, 267-293. 
Davies, T.R. and McSaveney, M.J., 2008. Principles of sustainable development on fans. Journal of Hydrology (New Zealand), 47, 43-65.

de Haas, T., Hauber, E., Conway, S.J., van Steijn, H., Johnsson, A., Kleinhans, M.G., 2015. Earthlike aqueous debris-flow activity on Mars at high orbital obliquity in the last million years. Nat. Commun. 6. DOI:10.1038/ncomms.

De Scally, F.A. and Owens, I.F., 2004. Morphometric controls and geomorphic responses on fans in the Southern Alps, New Zealand. Earth Surface Processes and Landforms, 29, 311-322.

Di Achille, G., and Hynek, B. M., 2010a. Deltas and valley networks on Mars: Implications for a global hydrosphere, in Lakes on Mars, edited by N. Cabrol and E. Grin. Chap. 8, Elsevier, New York.

Di Achille, G., and Hynek, B.M., 2010b. Ancient ocean on Mars supported by global distribution of deltas and valleys. Nat. Geosci., 3, 459-463, doi:10.1038/NGEO891.

Dickson, J.L., Head, J.W., and Fassett, C.I., 2012. Patterns of accumulation and flow of ice in the mid-latitudes of Mars during the Amazonian. Icarus, 219, pp. 723-732, 10.1016/j.icarus.2012.03.010.

Dickson, J.L., Kerber, L.A., Fassett, C.I., and Ehlmann, B.L., 2018. A global, blended CTX mosaic of Mars with vectorized seam mapping: A new mosaicking pipeline using principles of nondestructive image editing. Proc. Lunar Planet. Sci. Conf. 49th, abstract\#2480.

Ehlmann, B. L., et al., 2009. Identification of hydrated silicate minerals on Mars using MROCRISM: Geologic context near Nili Fossae and implications for aqueous alteration. J. Geophys. Res.,114, E00D08,DOI:10.1029/2009JE003339.

Elmaarry, M.R., Markiewicz, W.J., Mellon, M.T., et al., 2010. Crater floor polygons: Desiccation patterns of ancient lakes on Mars? J. Geophys. Res.-Planets 115, E10 0 06. DOI: 10.1029/2010JE0 03609.

Elmaarry, M.R., Kodikara, J., Wijessoriya, S., Markiewicz, W.J., Thomas, N., 2012. Desiccation mechanism for formation of giant polygons on Earth and intermediate-sized polygons on Mars: Results from a pre-fracture model. Earth Planet. Sci. Lett. 323-324, 19-26. 
892 Fassett, C.I., and Head, J.W., 2008. The timing of martian valley network activity: constraints from 893 buffered crater counting. Icarus, 195, pp. 61-89, 10.1016/j.icarus.2007.12.009

894 Fastook, J. L., Head, J. W., Marchant, D. R., Forget, F., and Madeleine, J.-B., 2012. Early Mars 895 climate near the Noachian-Hesperian boundary: Independent evidence for cold conditions from 896 basal melting of the south polar ice sheet (Dorsa Argentea Formation) and implications for valley 897 network formation. Icarus, 219(1), 25-40. https://doi.org/10.1016/j.icarus.2012.02.013.

898 Fastook, J.L., and Head, J.W., 2015. Glaciation in the Late Noachian Icy Highlands: Ice 899 accumulation, distribution, flow rates, basal melting, and top-down melting rate sand patterns. 900 Planetary and Space Science, 106, 82-98.

901 Ferguson, R., 2007. Flow resistance equations for gravel- and boulder-bed streams. Water Resour. 902 Res. 43, W05427. http://dx.doi.org/10.1029/2006WR005422

903 Fergason, R. L, Hare, T. M., Laura, J., 2018. HRSC and MOLA Blended Digital Elevation Model 904 at $200 \quad \mathrm{~m}$ v2, Astrogeology PDS Annex, U.S. Geological Survey. 905 http://bit.ly/HRSC_MOLA_Blend_v0.

906 Flahaut, J., Mustard, J.F., Quantin, C., Clenet, H., Allemand, P., and Thomas, P., 2010. Dikes of 907 distinct composition intruded into Noachian-aged crust exposed in the walls of Valles Marineris. 908 Geophysical Research Letters, 38, 15.

909 Flahaut, J., Quantin, C., Clenet, H., Allemand, P., Mustard, J.F., Thomas, P., 2012. Pristine 910 Noachian crust and key geologic transitions in the lower walls of Valles Marineris: Insights into 911 early igneous processes on Mars. Icarus, 221, 420-435.

912 Forget, F., Haberle, R. M., Montmessin, F., Levrard, B., and Head, J. W., 2006. Formation of 913 glaciers on Mars by atmospheric precipitation at high obliquity. Science, 311( 5759), 368- 371.

914 Ghail, R.C., and Hutchison, J.E., 2003. An alluvial fan at Apollinaris Patera, Mars. LPSC 2003. 915 \#Abstract 1775.

916 Ghatan, G.J., and Head, J.W., 2002. Candidate subglacial volcanoes in the south polar region of 917 Mars: Morphology, morphometry, and eruption conditions. Journal of Geophysical Research, 107, 918 E7. 
919 Goldspiel, J.M., and Squyres, S.W., 2011. Groundwater discharge and gully formation on martian 920 slopes. Icarus, 211, 238-258.

921 Grant, J. A., and Wilson, S. A., 2011. Late alluvial fan formation in southern Margaritifer Terra, 922 Mars. Geophys. Res. Lett., 38, L08201, DOI:10.1029/2011GL046844.

923 Grant, J. A., and Wilson, S. A., 2012. A possible synoptic source of water for alluvial fan formation 924 in Southern Margaritifer Terra, Mars. Planet. Space Sci., 72(1), 44- 52.

925 Gulick, V. C., 2001. Origin of the valley networks on Mars: A hydrological perspective, 926 Geomorphology, 37, 241-268, doi:10.1016/S0169-555X(00)00086-6.

927 Hallet, B., Sletten, R.S., Stewart, W., et al., 2013. Fracture Networks, Gale Crater, Mars. In: 928 Proceedings of 44th LPSC. \#Abstract No. 3108.

929 Hamilton, V. E., and Christensen, P. R., 2005. Evidence for extensive, olivine-rich bedrock on 930 Mars. Geology, 33(6), 433-436. https://doi.org/10.1130/G21258.1

931 Hartmann, W. K., and Neukum, G., 2001. Cratering chronology and the evolution of Mars. Space 932 Sci. Rev., 96, 165-194, DOI:10.1023/A:1011945222010.

933 Hartmann, W.K., Thorsteinsson, T., Sigurdsson, F., 2002. Comparison of Icelandic and martian 934 hillside gullies. Lunar and Planet. Sci. XLIII. Abstract \#1904.

935 Hartmann, W.K., Thorsteinsson, T., Sigurdsson, F., 2003. Martian hillside gullies and Icelandic 936 analogs. Icarus 162, 259-277.

937 Hartmann, W. K., Ansan, V., Berman, D. C., Mangold, N., and Forget, F., 2014. Comprehensive 938 analysis of glaciated Martian crater Greg. Icarus, 228, 96- 120. 939 https://doi.org/10.1016/j.icarus.2013.09.016.

940 Hauber, E., Gasselt, S.V., Ivanov, B., Werner, S., Head, J.W., Neukum, G., Jaumann, R., Greeley, 941 R., Mitchell, L. K., Muller, P., and The HRSC Co-Investigator Team, 2005. Discovery of a flank 942 caldera and very young glacial activity at Hecatus Tholus, Mars. Nature 434, 356-361. 943 https://doi.org/10.1038/nature03423 
944 Head, J. W., \& Pratt, S., 2001. Extensive Hesperian-aged south polar ice sheet on Mars: Evidence 945 for massive melting and retreat, and lateral flow and ponding of meltwater. Journal of Geophysical 946 Research, 106( E6), 12275- 12299. https://doi.org/10.1029/2000JE001359.

947 Head, J. et al., 2005. Tropical to mid-latitude snow and ice accumulation, flow, and glaciation on 948 Mars. Nature 434, 346-351.

949 Head, J.W. and Merchant, D.R., 2014. The climate history of early Mars: insights from the 950 Antarctic McMurdo Dry Valleys hydrologic system. Antarctic Science 26(6), 774-800.

951 Hoke, M. R. T., and Hynek, B. M., 2009. Roaming zones of precipitation on ancient Mars as 952 recorded in valley networks, J. Geophys. Res., 114, E08002, doi:10.1029/2008JE003247.

953 Huang, J., Edwards, C. S., Horgan, B. H. N., Christensen, P. R., Kraft, M. D., and Xiao, L., 2012. 954 Identification and mapping of dikes with relatively primitive compositions in Thaumasia Planum 955 on Mars: Implications for Tharsis volcanism and the opening of Valles Marineris. Geophys. Res. 956 Lett., 39, L17201, DOI:10.1029/2012GL052523.

957 Irwin, R. P., Howard, A. D., Craddock, R. A., Moore, and J. M., 2005. An intense terminal epoch 958 of widespread fluvial activity on early Mars: 2. Increased runoff and paleolake development, J. 959 Geophys. Res., 110, E12S15, doi:10.1029/2005JE002460.

Irwin, R. P., Wray, J. J., Mest, S. C., \& Maxwell, T. A. (2018). Wind-Eroded Crater Floors and 961 Intercrater Plains, Terra Sabaea, Mars. Journal of Geophysical Research: Planets, 123(2), 445962 467. https://doi.org/10.1002/2017JE005270

963 Ivanov, B. A., 2001. Mars/Moon cratering rate ratio estimates. Space Sci. Rev., 96, 87-104, 964 doi:10.1023/A:1011941121102.

965 Jorgenson, M. T., Shur, Y. L., and Pullman, E. R., 2006. Abrupt increase in permafrost degradation 966 in Arctic Alaska. Geophys. Res. Lett., 33, L02503, DOI:10.1029/ 2005GL024960.

967 Kargel, J.S., and Strom, R.G., 1992. Ancient glaciation on Mars. Geology, 20 (1), 3-7.

968 Kerber, L., Dickson, J.L., Head, J.W., Grosfils, E.B., 2017. Polygonal ridge networks on Mars: 969 Diversity of morphologies and the special case of the Eastern Medusae Fossae Formation. Icarus 970 281, 200-219.https://doi.org/10.1016/j.icarus.2016.08.020. 
971 King, T. V. V., and Ridley, W. I., 1987. Relation of the spectroscopic reflectance of olivine to 972 mineral chemistry and some remote sensing implications, J. Geophys. Res., 92, 11,457-11,469, DOI:10.1029/JB092iB11p11457.

Kite, E. S., Harvey, I., Kahre, M. A., Wolff, M. J., and Manga, M., 2013. Seasonal melting and the formation of sedimentary rocks on Mars, with predictions for the Gale crater mound. Icarus, 223, 131- 210, DOI:10.1016/j.icarus.2012.11.034.

Kite, E. S., Sneed, J., Mayer, D. P., and Wilson, S. A., 2017. Persistent or repeated surface habitability on Mars during the late Hesperian - Amazonian. Geophys. Res. Lett., 44, 3991-3999. DOI:10.1002/2017GL072660.

Kleinhans, M.G., 2005. Flow discharge and sediment transport models for estimating a minimum timescale of hydrological activity and channel and delta formation on Mars. J. Geophys. Res. 110, E12003. http://dx.doi.org/ 10.1029/2005JE002521.

Klima, R. L., Pieers, C. M., and Dyar, M. D., 2007. Spectroscopy of synthetic Mg-Fe pyroxenes I: Spin-allowed and spin-forbidden crystal field bands in the visible and near-infrared. Meteorit. Planet. Sci, 42, 235-253, DOI:10.1111/j.1945-5100.2007.tb00230.x.

Kostaschuk, R.A., MacDonald, G.M. and Putnam, P.E., 1986. Depositional process and alluvial fan-drainage basin morphometric relationships near Banff, Alberta, Canada. Earth Surface Processes and Landforms, 11, 471-484.

Kraal, E. R., Asphaug, E., Moore, J. M., Howard, A., and Bredt, A., 2008. Catalogue of large alluvial fans in Martian impact craters. Icarus, 194, 101-110, DOI:10.1016/j.icarus.2007.09.028.

Kress, A. M., and Head, J. W., 2015. Late Noachian and early Hesperian ridge systems in the south circumpolar Dorsa Argentea Formation, Mars: Evidence for two stages of melting of an extensive late Noachian ice sheet. Planetary and Space Science, 109-110, 1- 20. https://doi.org/10.1016/j.pss.2014.11.025

Lachenbruch, A.H., 1963. Contraction theory of ice-wedge polygons: A qualitative discussion. In: Proceedings of International Permafrost Conference, Proceedings, Lafayette, Indiana. National Academy of Sciences, National Research Council Publication No. 1287, pp. 63-71. 
998 Lamb, M.P., Dietrich, W.E., Sklar, L.S., 2008. A model for fluvial bedrock incision by impacting 999 suspended and bedload sediment. J. Geophys. Res. 113, F03025. 1000 http://dx.doi.org/10.1029/2007JF000915.

1001 Levy, J.S., Head, J., Marchant, D., 2009. Thermal contraction crack polygons on Mars: 1002 Classification, distribution, and climate implications from HiRISE observations. J. Geophys. Res. 1003 114. doi: 10.1029/20 08JE0 03273.

1004 Mackay, J. R., 2000. Thermally induced movements in ice-wedge polygons, western arctic coast: 1005 A long-term study. Ge' ogr. Phys. Quaternaire, 54,41-68.

1006 Malin, M.C., and Edgett, K.S., 2000. Sedimentary rocks of early Mars. Science, 290, 1927-1937.

1007 Malin, M. C., et al., 2007. Context Camera investigation onboard the Mars Reconnaissance 1008 Orbiter. J. Geophys. Res., 112, E05S04, doi:10.1029/2006JE002808.

1009 Mangold, N., 2005. High latitude patterned grounds on Mars: Classification, distribution, and 1010 climatic control. Icarus 174, 336-359.

1011 Mangold, N., Adeli, S., Conway, S., Ansan, V., Langlais, B., 2012a. A chronology of early Mars 1012 climatic evolution from impact crater degradation. J. Geophys. Res.-Planets, 117, E4, 1013 doi:10.1029/2011JE004005.

1014 Mangold, N., Carter, J., Poulet, F., Dehouck, E., Ansan, V., Loizeau, D., 2012b. Late Hesperian 1015 aqueous alteration at Majuro crater, Mars. Planetary and Space Science, 72, 18-30.

1016 Mangold, N., 2012. Fluvial landforms on fresh impact ejecta on Mars, Planetary and Space 1017 Science, 62, 69-85.

1018 Mangold N., Kite, E.S., Kleinhans, M.G., Newsom, H., Ansan, V., Hauber, E., Kraal, E., Quantin, 1019 C., Tanaka, K, 2012c. The origin and timing of fluvial activity at Eberswalde crater, Mars. Icarus, $1020220,530-551$.

1021 Mattern, E., Matas, J., Ricard, Y., Bass, J., 2005. Lower mantle composition and temperature from 1022 mineral physics and thermodynamic modeling. Geophys.J. Int. 160, 973-990.

1023 McCauley, J.F., 1978. Geologic map of the Coprates quadrangle of Mars. DOI 10.3133/i897. 
1024

1025

1026

1027

1028

1029

1030

1031

1032

1033

1034

1035

1036

1037

1038

1039

1040

1041

1042

1043

1044

1045

1046

1047

1048

1049

1050

McEwen, A. S., et al., 2007. Mars Reconnaissance Orbiter's High-Resolution Imaging Science Experiment (HiRISE). J. Geophys. Res., 112, E05S02, DOI:10.1029/2005JE002605

McSween, H. Y., Jr., et al., 1999. Chemical, multispectral, and textural constraints on the composition and origin of rocks at the Mars Pathfinder landing site. J. Geophys. Res., 104, 86798715, DOI:10.1029/98JE02551.

McSween, H. Y., et al., 2006. Characterization and petrologic interpretation of olivine-rich basalts at Gusev Crater, Mars. J. Geophys. Res., 111, E02S10, DOI:10.1029/2005JE002477.

Melton, M.A., 1965. The geomorphic and paleoclimatic significance of alluvial deposits in southern Arizona. Journal of Geology, 73, 1-38.

Mellon, M. T., et al., 2009. Ground ice at the Phoenix Landing Site: Stability state and origin. J. Geophys. Res., 114,E00E07, DOI:10.1029/2009JE003417.

Michael, G.G., 2013. Planetary surface dating from crater size-frequency distribution measurements: Multiple resurfacing episodes and differential isochron fitting. Icarus, 226, 885890.

Michael, G.G., Kneissl, T., Neesemann, A., 2016. Planetary surface dating from crater sizefrequency distribution measurements: Poisson timing analysis. Icarus, 227, 279-285.

Milton, D. J. (1973), Water and processes of degradation in the Martian landscape, J. Geophys. Res., 78, 4037- 4047.

Moore, J. M., Howard, A. D., Dietrich, W. E., and Schenk, P. M., 2003. Martian Layered Fluvial Deposits: Implications for Noachian Climate Scenarios. Geophys. Res. Lett., 30 (24), 2292, DOI:10.1029/2003GL019002.

Moore, J. M., and Howard, A. D., 2005. Large alluvial fans on Mars. J. Geophys. Res., 110, E04005, doi:10.1029/2004JE002352.

Morgan, A.M., Beyer, R.A., Howard, A.D., and Moore, J.M., 2012. The alluvial fans of Saheki crater. Lunar Planet. Sci. 43. Abstract \#2815.

Morgan, A.M., Howard, A.D., Hobley, D.E., Moore, J.M., Dietrich, W.E., Williams, R.M., Burr, D.M., Grant, J.A., Wilson, S.A. and Matsubara, Y., 2014. Sedimentology and climatic 
1051 environment of alluvial fans in the Martian Saheki crater and a comparison with terrestrial fans in 1052 the Atacama Desert. Icarus, 229, pp.131-156.

1053 Murchie, S., et al., 2007. Compact Reconnaissance Imaging Spectrometer for Mars (CRISM) on 1054 Mars Reconnaissance Orbiter (MRO). J. Geophys. Res., 112, E05S03, 1055 doi:10.1029/2006JE002682.

1056 Mustard, J.F., Poulet, F., Gendrin, A., Bibring, J.-P., Langevin, Y., Gondet, B., Mangold, 1057 N., Bellucci, G., Altieri, F., 2005. Olivine and pyroxene diversity in the crust of Mars. Science, 1058 307, 1594-1597.

1059 Mustard, J. F., Poulet, F., Head, J. W., Mangold, N., Bibring, J.-P., Pelkey, S. M., et al., 2007. 1060 Mineralogy of the Nili Fossae region with OMEGA/Mex data: 1 ancient impact melt in the Isidis 1061 basin and implications for the transition from the Noachian to Hesperian. Journal of Geophysical 1062 Research, 112, E08S03.

1063 Mustard, J. F., Ehlmann, B. L., Murchie, S. L., Poulet, F., Mangold, N., Head, J. W., Bibring, J.P., 1064 and Roach, L. H., 2009. Composition, Morphology, and Stratigraphy of Noachian Crust around 1065 the Isidis basin. J. Geophys. Res., 114, E00D12, DOI:10.1029/2009JE003349.

1066 Neal, J.T., Langer, A.M., Kerr, P.F., 1968. Giant desiccation polygons of Great Basin playas. Geol. 1067 Soc. Am. Bull. 79 (1), 69-90.

1068 Neukum, G. and Ivanov, B.A., 2001. Crater Production function on Mars. Proc. Lunar Planet. Sci. 1069 Conf. 32th, Abstract\#1757.

1070 Ody, A., Poulet, F., Bibring, J.P., Loizeau, D., Carter, J., Gondet, B., Langevin, Y., 2013. Global 1071 investigation of olivine on Mars: Insights into crust and mantle compositions. Journal of 1072 Geophysical Research, 118, 234-262.

1073 Oehler, D.Z., Mangold, N., Hallet, B., Fairén, A.G., Le Deit, L., Williams, A.J., Sletten, R.S. and 1074 Martínez-Frías, J., 2016. Origin and significance of decameter-scale polygons in the lower Peace 1075 Vallis fan of Gale crater, Mars. Icarus, 277, pp.56-72.

1076 Palumbo, A., and Head, J.W., 2017. Impact cratering as a cause of climate change, surface 1077 alteration, and resurfacing during the early history of Mars. Meteoritics and Planetary Science. 1078 https://doi.org/10.1111/maps.13001. 
Paterson, W.S.B., 1994. The Physics of Glaciers, third ed. Pergamon Press, New York. Phillips, L.O., Schumm, S.A., 1987. Effect of regional slope on drainage networks. Geology 15, 813-816. Pelkey, S. M., Mustard, J. F., Murchie, S., Clancy, R. T., Wolff, M., Smith, M., Milliken, R., Bibring, J.-P, Gendrin, A., Poulet, F., Langevin, Y., \& Gondet, B., 2007. CRISM multispectral summary products: Parameterizing mineral diversity on Mars from reflectance. Journal of Geophysical Research, 112, E08S14.

Poulet, F., Bibring, J.P., Langevin, Y., Mustard, J.F., Mangold, N., Vincendon, M., Gondet, B., Pinet, P., Bardintzeff, J.M., Platevoet, B., 2009a. Quantitative compositional analysis of martian mafic regions using the MEx/OMEGA reflectance data 1. Methodology, uncertainties and examples of application. Icarus, 201, 69-83.

Poulet, F., Mangold, N., Platevoet, B., Bardintzeff, J.-M., Sautter, V., Mustard, J.F., Bibring, J.P., Pinet, P.C., Langevin, Y., Gondet, B., Aléon-Toppani, A., 2009b. Quantitative compositional analysis of martian mafic regions using the MEx/OMEGA reflectance data 2. Petrological implications. Icarus, 201, 84-101.

Quantin-Nataf, C., Lozac'h, L., Thollot, P., Loizeau, D., Bultel, B., Fernando, J., Allemand, P., Dubuffet, F., Poulet, F., Ody, A., Clenet, H., Leyrat, C., \& Harrisson, S., 2018. MarsSI: Martian surface data processing information system. Planetary and Space Science, 150, 157- 170.

Quantin, C., Flahaut, J., Clenet, H. Allemand, P., Thomas, P., 2012. Composition and structures of the subsurface in the vicinity of Valles Marineris as revealed by central uplifts of impact craters. Icarus, 221, 436-452.

Robbins, S.J., and Hynek, B.M., 2012. A new global database of Mars impact craters $\geq 1 \mathrm{~km}$ : Global crater properties and regional variations of the simple-to-complex transition diameter. Journal of Geophysical Research, 117, E06001.

Rogers, A. D., Warner, N. H., Golombek, M. P., Head, J. W., and Cowart, J. C., 2018. Areally extensive surface bedrock exposures on Mars: Many are clastic rocks, not lavas. Geophysical Research Letters, 45, 1767-1777. https://doi.org/10.1002/2018GL077030 
1105 Salvatore, M. R., Mustard, J. F., Wyatt, M. B., and Murchie, S. L., 2010. Definitive evidence of 1106 Hesperian basalt in Acidalia and Chryse planitiae. J. Geophys. Res., 115, E7, 1107 DOI:10.1029/2009JE003519.

1108 Scanlon, K. E., Head, J. W., Wilson, L., and Marchant, D. R., 2014. Volcano-ice interactions in 1109 the Arsia Mons tropical mountain glacier deposits. Icarus, 237, 315- 339. 1110 https://doi.org/10.1016/j.icarus.2014.04.024.

1111 Scanlon, K. E., Head, J. W., and Marchant, D. R., 2015. Volcanism-induced, local wet-based 1112 glacial conditions recorded in the Late Amazonian Arsia Mons tropical mountain glacier deposits. 1113 Icarus, 250, 18-31. https://doi.org/10.1016/j.icarus.2014.11.016.

1114 Scott, D. H., and Tanaka, K. L., 1986. Geologic map of the western equatorial region of Mars. 1115 U.S. Geol. Surv. Misc. Invest. Ser. Map, I-1802-A.

1116 Shean, D.E., Head, J.W., Marchant, D.R., 2005. Origin and evolution of a cold-based tropical 1117 mountain glacier on Mars: The Pavonis Mons fan-shaped deposit. J.Geophys. Res. 110, E05001.

1118 Shean, D. E., 2010. Candidate ice-rich material within equatorial craters on Mars. Geophys. Res. 1119 Lett.,37,L24202, DOI:10.1029/2010GL045181.

1120 Skinner, J. A., Hare, T. M., and Tanaka, K. L., 2006. LPSC XXXVII, Abstract \#2331.

1121 Skok, J. R., Mustard, J. F., Murchie, S. L., Wyatt, M. B., and Ehlmann, B. L., 2010. Spectrally 1122 distinct ejecta in Syrtis Major, Mars: Evidence for environmental change at the Hesperian1123 Amazonian boundary. J. Geophys. Res., 115, E00D14, DOI:10.1029/2009JE003338.

1124 Skok, J. R., Mustard, J. F., Tornabene, L. L., Pan, C., Rogers, D., and Murchie, S. L., 2012. A 1125 spectroscopic analysis of Martian crater central peaks: Formation of the ancient crust. J. Geophys. 1126 Res.,117, E00J18, DOI:10.1029/2012JE004148.

1127 Sinha, R.K. and Vijayan, S., 2017. Geomorphic investigation of craters in Alba Mons, Mars: 1128 Implications for Late Amazonian glacial activity in the region. Planetary and Space Science, 144, 1129 32-48. https://doi.org/10.1016/j.pss.2017.05.014. 
1130 Smith, D. E., et al., 2001. Mars Orbiter Laser Altimeter: Experiment summary after the first year

1131 of global mapping of Mars. J. Geophys. Res., 106 (E10), 23689-23722, 1132 DOI:10.1029/2000JE001364.

1133 Soare, R.J., Conwat, S.J., Dohm, J.M., 2014. Possible ice-wedge polygons and recent landscape 1134 modification by "wet" periglacial processes in and around the Argyre impact basin, Mars. Icarus, 1135 233, 214-228. https://doi.org/10.1016/j.icarus.2014.01.034.

1136 Sun, V. Z., and Milliken, R. E., 2015. The geology and mineralogy of Ritchey crater, Mars: 1137 Evidence for post-Noachian clay formation. Journal of Geophysical Research: Planets, 119, 8101138 836. https://doi:10.1002/2013JE004602.

1139 Sunshine, J. M., Pieters, C. M. and Pratt, S. F., 1990. Deconvolution of mineral absorption bands: 1140 An improved approach. J. Geophys. Res., 95, 6955-6966, DOI:10.1029/JB095iB05p06955.

1141 Sunshine, J. M., and Pieters, C. M., 1998. Determining the composition of olivine from reflectance 1142 spectroscopy. J. Geophys. Res., 103, 13,675-13,688, DOI:10.1029/98JE01217.

1143 Tanaka, K.L., Skinner, J.A., Dohm, J.M., Irwin, R.P., Kolb, E.J., Fortezzo, C.M., Platz, T., 1144 Michael, G.G., and Hare, T.M., 2014, Geologic map of Mars: U.S. Geological Survey Scientific 1145 Investigations Map 3292, scale 1:20,000,000, pamphlet 43 p., https://dx.doi.org/10.3133/sim3292.

1146 Goudge, T.A., Milliken, R. E.,.Head, J. W., Mustard, J. F., Fassett, C.I., 2017. Sedimentological 1147 evidence for a deltaic origin of the western fan deposit in Jezero crater, Mars and implications for 1148 future exploration. Earth and Planetary Science Letters, 458, 357-365. 1149 https://doi.org/10.1016/j.epsl.2016.10.056

1150 Tornabene, L. L., Moersch, J. E., McSween, H. Y., Hamilton, V. E., Piatek, J. L., and Christensen, 1151 P. R., 2008. Surface and crater-exposed lithologic units of the Isidis Basin as mapped by coanalysis 1152 of THEMIS and TES derived data products. Journal of Geophysical Research, 113, E10001. 1153 https://doi.org/10.1029/2007JE002988

1154 Ventra, D., and Clarke, L. E., 2018. Geology and Geomorphology of Alluvial and Fluvial Fans: 1155 Terrestrial and Planetary Perspectives. Geological Society, London, Special Publications, 440, 1115621. 
1157 Viviano-Beck, C. E., et al., 2014. Revised CRISM spectral parameters and summary products

1158 based on the currently detected mineral diversity on Mars. J. Geophys. Res. Planets, 119, 14031159 1431, DOI:10.1002/2014JE004627.

1160 Viviano-Beck, C. E. et al., 2015. MRO CRISM Type Spectra Library, NASA Planetary Data 1161 System. http://crismtypespectra.rsl.wustl.edu

1162 Viviano-Beck, C.E., Mucrchie, S.L., Daubar, I.J., Morgan, M.F., Seelos, F.P., Plescia, J.B., 2019. 1163 Composition of Amazonian volcanic material in Tharsis and Elysium, Mars, from MRO/CRISM 1164 reflectance spectra. Icarus 328, 274-286. https://doi.org/10.1016/j.icarus.2019.03.001.

1165 Washburn, A.L., 1980. A survey of periglacial processes and environments. Geocryology, The 1166 Blackburn Press, New Jersey.

1167 Weiss, D.K., Head, J.W., 2016. Impact ejecta induced melting of surface ice deposits on Mars. 1168 Icarus 280, 205-233.doi:10.1016/j.icarus.2016.07.007.

1169 Williams, K., Toon, O., Heldmann, J., and Mellon, M., 2009. Ancient melting of mid-latitude 1170 snowpacks on mars as a water source for gullies. Icarus, 200, 418-425.

1171 Wilson, L., Ghatan, G.J., Head, J.W., Mitchell, K.L., 2004. Mars outflow channels: A reappraisal 1172 of the estimation of water flow velocities from water depths, regional slopes, and channel floor 1173 properties. J. Geophys. Res. E: Planets 109, E09003, 1-10.

1174 Wilson, S.A., Zimbelman, J.R., 2004. Latitude-dependent nature and physical characteristics of 1175 transverse aeolian ridges on Mars. J. Geophys. Res. E: Planets 109, E10003. 1176 http://dx.doi.org/10.1029/2004JE002247.

1177 Wilson, S. A., Grant, J. A., and Howard, A. D., 2013. Inventory of equatorial alluvial fans and 1178 deltas on Mars. Lunar and Planet. Sci. Conf., Abstract 2710.

1179 Wilson, S.A., Morgan, A.M., Howard, A.D., and Grant, J.A., 2021. The global distribution of 1180 craters with alluvial fans and deltas on Mars. Geophysical Research Letters, DOI: 1181 https://doi.org/10.1029/2020GL091653 
1182 Wordsworth, R., Forget, F., Millour, E., Head, J. W., Madeleine, J. B., and Charnay, B., 2013. 1183 Global modeling of the early Martian climate under a denser CO2 atmosphere: Water cycle and 1184 ice evolution. Icarus, 222 ( 1), 1- 19, DOI:10.1016/j.icarus.2012.09.036.

1185 Xiao, L., Huang, J., Christensen, P. R., Greeley, R., Williams, D. A., Zhao, J., and He, Q., 2012. 1186 Ancient volcanism and its implication for thermal evolution of Mars, Earth Planet. Sci. Lett., 323$1187324,9-18$.

1188 Yoshikawa, K., 2003. Origin of the polygons and the thickness of Vastitas Borealis Formation in 1189 Western Utopia Planitia on Mars. Geophys. Res. Lett., 30 (12), 1603, 1190 DOI:10.1029/2003GL017165. 